\title{
Small molecules derived carbon dots: synthesis and applications in sensing, catalysis, imaging, and biomedicine
}

Anirudh Sharma and Joydeep Das*

\begin{abstract}
Carbon dots (CDs) are the new fellow of carbon family having a size less than $10 \mathrm{~nm}$ and attracted much attention of researchers since the last decade because of their unique characteristics, such as inexpensive and facile synthesis methods, easy surface modification, excellent photoluminescence, outstanding water solubility, and low toxicity. Due to these unique characteristics, CDs have been extensively applied in different kind of scientific disciplines. For example in the photocatalytic reactions, drug-gene delivery system, in vitro and in vivo bioimaging, chemical and biological sensing as well as photodynamic and photothermal therapies. Mainly two types of methods are available in the literature to synthesize CDs: the top-down approach, which refers to breaking down a more massive carbon structure into nanoscale particles; the bottom-up approach, which refers to the synthesis of CDs from smaller carbon units (small organic molecules). Many review articles are available in the literature regarding the synthesis and applications of CDs. However, there is no such review article describing the synthesis and complete application of CDs derived from small organic molecules together. In this review, we have summarized the progress of research on CDs regarding its synthesis from small organic molecules (bottom-up approach) via hydrothermal/solvothermal treatment, microwave irradiation, ultrasonic treatment, and thermal decomposition techniques as well as applications in the field of bioimaging, drug/gene delivery system, fluorescence-based sensing, photocatalytic reactions, photo-dynamic therapy (PDT) and photo-thermal (PTT) therapy based on the available literature. Finally, the challenges and future direction of CDs are discussed.
\end{abstract}

Keywords: Carbon dots, Biomedical applications, Hydrothermal/microwave synthesis, Photocatalysis, Sensing

\section{Introduction}

Nano-crystals of carbon materials having dimensions smaller than $10 \mathrm{~nm}$ is known as carbon quantum dots (CDs) [1]. They exhibit different size reliant optical properties such as photoluminescence, chemiluminescence, electrochemical luminescence and photoinduced electron transfer $[1,2]$. Besides, the high aqueous dispersibility, biocompatibility, good elasticity in modification, high resistance to photobleaching and chemical inertness make it well applicable in bio-imaging [3, 4], bio-sensing $[5,6]$, chemical-sensing [7], and biomedical applications

\footnotetext{
*Correspondence: joydeepdas@shooliniuniversity.com; jdchem83@gmail.com

School of Chemistry, Shoolini University of Biotechnology

and Management Sciences, Bajhol, PO Sultanpur, Solan, HP 173229, India
}

[8]. Being a new kind of fluorescent nanomaterial and having excellent biocompatibility, CDs are widely used in the area of bio-imaging both in vitro and in vivo and in diagnosis purposes [9], Photothermal as well as photodynamic therapy and drug/gene delivery carriers $[10$, 11]. CDs could also been applied for the determination of cellular levels of biomolecules and ions (bio-sensor), such as $\mathrm{Cu}^{2+}$ [12], $\mathrm{Hg}^{2+}$ [13], $\mathrm{NO}_{3}^{-}$[14], $\mathrm{C}_{6} \mathrm{H}_{12} \mathrm{O}_{6}$ [15], $\mathrm{pH}$ [16], $\mathrm{H}_{2} \mathrm{O}_{2}$ [17], etc. CDs could also act as a promising photocatalyst after co-doping with heteroatoms, such as nitrogen, phosphorus, sulfur, and certain metal ions, such as $\mathrm{Cu}, \mathrm{Zn}, \mathrm{Ti}$, etc. Incorporation of these elements improves the electron-donation/acceptance ability of the CDs and promotes redox reaction on the surface of CDs [18]. These properties of CDs are being employed for wastewater treatment and hydrogen generation $[19,20]$. 
In 2004, during electrophoretic purification of singlewalled carbon nanotubes (SWCNTs) fluorescent carbon nanoparticles were accidentally discovered by $\mathrm{Xu}$ et al. [21], and 2 years later Sun et al. synthesized CDs from graphite powder and cement using a laser ablation technique [22]. Mainly two types of methods are available in the literature for the synthesis of CDs; top-down approach and bottom-up approach. Top-down approach refers to breaking down larger carbon structures, such as carbon nanotubes and graphite into smaller carbon structures having dimensions less than $10 \mathrm{~nm}$ using arc discharge, laser ablation and electrochemical methods [23]. One such electrochemical method was adopted by Wang et al. for the synthesis of CDs from MWCNTs [24]. Bottom-up approach refers to the synthesis of CDs from smaller carbon units (small organic molecules) by electrochemical/chemical oxidation, laser ablation, hydrothermal/solvothermal treatment, microwave irradiation, ultrasonic treatment, and thermal decomposition techniques [25]. For example, Zhu et al. synthesized CDs via by heating a solution of poly (ethylene glycol) and saccharide in $500 \mathrm{~W}$ microwave oven for 2 to $10 \mathrm{~min}$ [26].

Various chemical precursors have been identified as the source of CDs, such as citric acid [27], glycerol [28], L-ascorbic acid [29], glucose [30], citric acid-urea [31] and thiourea [32]. To convert these precursors into fluorescent CDs various synthetic processes are used, such as ultrasonication [33], simple heating [34], arc discharge [35], solvothermal [36], hydrothermal [37-39], chemical oxidation [40], and laser ablation [41]. Plentiful efforts have been made to expand the usability of CDs to fulfill the growing demand for high-performance techniques, such as bio-imaging, drug-gene delivery, chemical sensing, as well as photocatalysis. However, it is also necessary to regulate the dimensions of CDs during its synthesis to attain uniform properties for a particular application. A large number of reports established the methods of purifying the as-prepared CDs via post-treatment, for example, centrifugation, filtration, gel-electrophoresis and column chromatography [42, 43]. Besides, monitoring the dimensions of CDs during its formation is also preferred.

In the past few years, many review articles have been published on the synthesis, properties and applications CDs which are derived from either small organic molecules (chemical) or green sources [44]. However, the number of review articles on CDs, which describe its synthesis only from chemical precursors and applications, like fluorescence-based sensing, bio-imaging, photocatalysis, drug/gene delivery carriers, photothermal as well as photodynamic therapy is still limited, and this article made an effort to fill the gap. In this current review article, we have described the recent progress of small molecule-derived CDs in the field of biomedical as well as chemical applications to date and their future perspective.

\section{Methods of synthesis of CDs}

CDs can be synthesized mainly via two routes: (i) topdown approach and (ii) bottom-up approach (Fig. 1). Top-down approach refers to breaking down larger carbon structures via chemical oxidation, discharge, electrochemical oxidation, and ultrasonic methods [25]. However, drawbacks of this approach includes the requirement of expensive materials, harsh reaction conditions, and long reaction time [45]. On the other hand, the bottom-up approach refers to the conversion of smaller carbon structure into CDs of the desired size. This bottom-up approach is consisting of hydrothermal treatment, ultrasonic treatment, thermal decomposition, pyrolysis, carbonization, microwave synthesis and solvothermal method to synthesize CDs. Here we will discuss both the top-down and bottom-up approach for the synthesis of CDs obtained from small organic molecules.

\section{Top-down approach}

Table 1 summarizes the several methods which are used for CD synthesis via the Top-down approach.

\section{Electrochemical/chemical oxidation}

Electrochemical/chemical oxidation is the most common top-down synthetic route for the synthesis of CDs, because of several remarkable advantages, such as high yield, high purity, low cost, and easy control over size. However, only a few articles are reported, so far regarding the electrochemical oxidation of small molecules to synthesize CDs. Zhou et al. demonstrated the first synthesis of CDs from carbon nanotube via electrochemical oxidation method [26]. Later, Ray et al. used carbon soots as the carbon source for the synthesis of CDs, and this approach can be used for the mg scale synthesis of CDs [40].

Peng et al. fabricated TTDDA passivated CDs with an average size of $5 \mathrm{~nm}$ from carbohydrates by dehydrating with conc. $\mathrm{H}_{2} \mathrm{SO}_{4}$ [46]. Fabrication of CDs from low molecular-weight alcohols was reported by Deng et al. [47]. They observed that the diameter of CDs was highly dependent upon applied potentials [47]. Hou et al. synthesized CDs from sodium citrate, and urea and the observed diameter of the CDs were in the range of 1.0 to $3.5 \mathrm{~nm}$ with $11.4 \%$ quantum yield (QY) [48]. Liu et al. used graphite electrode as the carbon source to synthesize CDs with an average diameter of $4 \pm 0.2 \mathrm{~nm}$ [49]. 


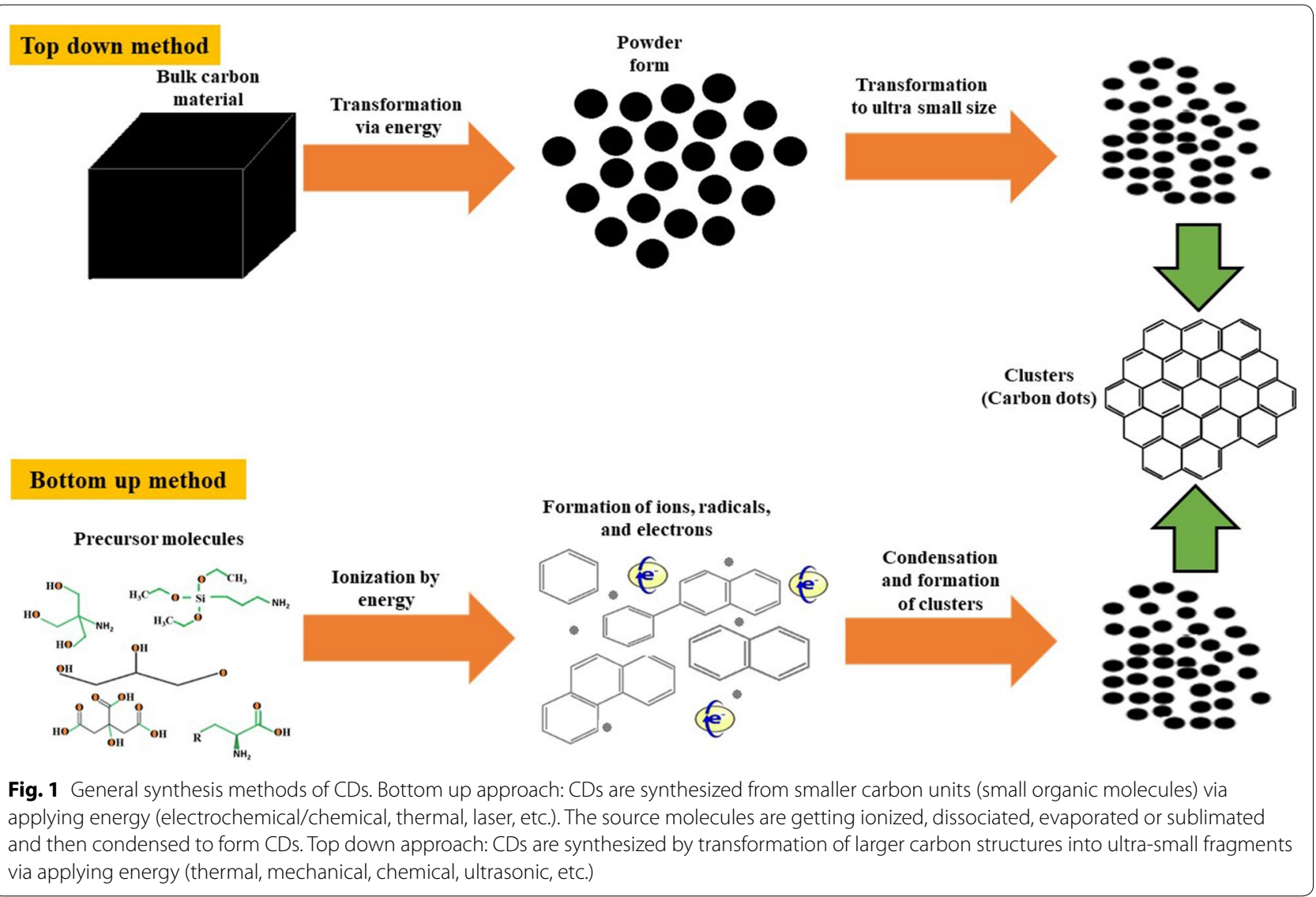

Table 1 Synthesis of CDs from small organic molecules via a top-down approach

\begin{tabular}{|c|c|c|c|c|c|c|}
\hline S. No. & Source & Method of preparation & $\begin{array}{l}\text { Doping }(d) / \text { surface } \\
\text { passivating }(p) \text { agent }\end{array}$ & Color & Size $(\mathrm{nm})$ & Refs. No. \\
\hline 1. & Carbon nanotube & Electrochemical synthesis & - & Blue & $2.8 \pm 0.5$ & [26] \\
\hline 2. & Carbon soot & Chemical oxidation & - & Green & $2-6$ & [40] \\
\hline 3. & Carbohydrates & Chemical oxidation & $\begin{array}{l}\text { (TTDDA) 4,7,10-trioxa- } \\
\text { 1,13-tridecanediamine } \\
\text { (P) }\end{array}$ & $\begin{array}{l}\text { Red, blue, green and } \\
\text { yellow }\end{array}$ & 5 & [46] \\
\hline 4. & $\begin{array}{l}\text { Low-molecular-weight } \\
\text { alcohols }\end{array}$ & Electrochemical synthesis & - & Red and blue & $2.1,2.9,3.5$, and 4.3 & [47] \\
\hline 5. & Sodium citrate and urea. & Electrochemical synthesis & - & Blue & $1.0-3.5$ & [48] \\
\hline 6. & Graphite electrode & Electrochemical synthesis & - & Bright yellow & $4 \pm 0.2$ & [49] \\
\hline 7. & Toluene & Laser ablation & - & Red, black and blue & $\begin{array}{l}2-3.9,3-10.0 \\
10-17.2 \text { and } \\
13-20.5\end{array}$ & [41] \\
\hline 8. & Graphite powders & Laser ablation & - & Red, black and blue & $1.5,1.6$, and 1.8 & [50] \\
\hline 9. & $\begin{array}{l}\text { Ascorbic acid and } \\
\text { ammonia }\end{array}$ & Ultrasonic treatment & $N(d)$ & Blue, green & 3.36 & [51] \\
\hline 10. & Oligomer polyamide resin & Ultrasonic treatment & Silane coupling agent (p) & Bright white & $2-4$ & [33] \\
\hline
\end{tabular}

\section{Laser ablation}

Laser ablation is another standard method used by the researchers for the synthesis of CDs. Yu et al. prepared
CDs using toluene as the carbon source via laser irradiation technique. They controlled the size of CDs using laser furnace [41]. Nguyen et al. reported the synthesis 
of CDs from graphite powders via femtosecond laser ablation. They observed that the size of CDs and photoluminescence properties could easily be controlled by changing the parameters including spot size, irradiation time and laser fluence. Smaller size CDs can be synthesized by increasing the irradiation time [50].

\section{Ultrasonic treatment}

Ultrasonic treatment is also a very convenient method as the large carbon materials can be broken down by the action of very high energy of ultrasonic sound wave. Wang et al. synthesized $\mathrm{N}$-doped CDs from ascorbic acid and ammonia via ultrasonic treatment [51]. Dang et al. fabricated CDs using oligomer-polyamide resin as the carbon source by ultrasonic treatment. The as-prepared CDs were well dispersed, had low crystallinity, and functional groups at the surface [33].

\section{Bottom-up approach}

\section{Hydrothermal synthesis}

Hydrothermal synthesis method is being used by most of the researchers as a cheap, eco-friendly and lowcost route to synthesize CDs from saccharides, amines, organic acids and their derivatives (Table 2) [13, 52]. Zhang et al. synthesized fluorescent CDs for the first time from small organic compound, L-ascorbic acid via hydrothermal method. They heated the aqueous solution ascorbic acid at a constant $180{ }^{\circ} \mathrm{C}$ temperature for $4 \mathrm{~h}$ in an autoclave and purified the water-phase solution via dialysis using 8000-14,000 MWCO membrane. The as-prepared CDs had a diameter of $2 \mathrm{~nm}$ [53]. Qu et al. synthesized CDs from dopamine using this method. They heated the aqueous solution of dopamine at $180^{\circ} \mathrm{C}$ temperature for $6 \mathrm{~h}$ in an autoclave and purified via centrifugation. The synthesized CDs were mostly spherical with an average diameter of about $3.8 \mathrm{~nm}$ [37]. Li et al.

\section{Table 2 Synthesis of CDs from small organic molecules via hydrothermal treatment}

\begin{tabular}{|c|c|c|c|c|c|c|}
\hline S. No. & Source & Method of preparation & $\begin{array}{l}\text { Doping }(d) / \text { surface } \\
\text { passivating }(p) \text { agent }\end{array}$ & Color & Size $(\mathrm{nm})$ & Refs. No. \\
\hline 1. & L-Ascorbic acid & Hydrothermal treatment & - & Violet & 2 & {$[53]$} \\
\hline 2. & Glucosamine $\mathrm{HCl}$ & Hydrothermal treatment & Glucosamine $\mathrm{HCl}(\mathrm{d})$ & Green & $15-70$ & {$[57]$} \\
\hline 3. & Glucose, monopotassium phosphate & Hydrothermal treatment & - & Violet & $1.83-3.83$ & {$[57]$} \\
\hline 4. & Dopamine & Hydrothermal treatment & - & Blue, yellow, green & 3.8 & {$[37]$} \\
\hline 5. & Sodium citrate & Hydrothermal treatment & - & Blue & 1.59 & {$[13]$} \\
\hline 6. & Citric acid and ethylene diamine & Hydrothermal treatment & - & Blue & $2-6$ & {$[58]$} \\
\hline 7. & bPEl, ammonium persulfate & Hydrothermal synthesis & bPEl & Blue & $3-4$ & {$[59]$} \\
\hline 8. & Streptomycin & Hydrothermal treatment & - & Violet & 2.97 & {$[60]$} \\
\hline 9. & Histidine, $\mathrm{NaOH}$ & Hydrothermal treatment & - & Blue & $3-5$ & {$[61]$} \\
\hline 10. & Ammonium citrate, ethylenediamine & Hydrothermal treatment & $N(d)$ & Blue & 4.8 & {$[54]$} \\
\hline 11. & L-Serine, L-cystine & Hydrothermal treatment & $N, S(d)$ & Orange & 2.6 & {$[55]$} \\
\hline 12. & $\begin{array}{l}\text { 1-Octadecane 1-hexadecylamine, } \\
\text { citric acid }\end{array}$ & Hydrothermal synthesis & Dihydrolipoic acid (p) & Yellow & $6-8$ & {$[62]$} \\
\hline 13. & Citric acid & Hydrothermal treatment & Isoleucine $(d)$ & Violet & $6-15$ & {$[63]$} \\
\hline 14. & Ammonium citrate & Hydrothermal treatment & Ethylene diamine $(\mathrm{d})$ & Indigo & 4.8 & {$[54]$} \\
\hline 15. & Citric acid, ethanediamine & Hydrothermal method & - & Violet & $<5$ & {$[64]$} \\
\hline 16. & L-Serine, L-cystine & Hydrothermal treatment & $N, S(d)$ & Orange & 2.6 & {$[55]$} \\
\hline 17. & Citric acid, GSH & Hydrothermal treatment & - & Blue & $2.5-3$ & {$[65]$} \\
\hline 18. & $\begin{array}{l}\text { 1-Octadecane 1-hexadecylamine, } \\
\text { citric acid }\end{array}$ & Hydrothermal synthesis & Dihydrolipoic acid (p) & Yellow & $6-8$ & {$[62]$} \\
\hline 19. & Citric acid, $\mathrm{NaOH}$ & Hydrothermal treatment & - & Green & 11.3 & {$[66]$} \\
\hline 20. & Citric acid, $\mathrm{NH}_{3} \cdot \mathrm{H}_{2} \mathrm{O}$ & Hydrothermal treatment & $N(d)$ & Blue & 2 & {$[6]$} \\
\hline 21. & Folic acid, phosphoric acid & Hydrothermal treatment & Folic acid, phosphoric acid (d) & Indigo & $13.2 \pm 1.6$ & {$[67]$} \\
\hline 22. & Glucose & Hydrothermal treatment & - & Blue & 1.65 & {$[68]$} \\
\hline 23. & Sodium nitrate, histidine & Hydrothermal treatment & - & Indigo & 1.5 & {$[69]$} \\
\hline 24. & L-Phenylalaninol & Hydrothermal carbonization & - & Violet & 2.8 & {$[38]$} \\
\hline 25. & Folic acid, phosphoric acid & Hydrothermal treatment & Folic acid, phosphoric acid (d) & Indigo & $13.2 \pm 1.6$ & {$[67]$} \\
\hline 26. & $\begin{array}{l}\text { APTS (3-Aminopropyl)triethoxysi- } \\
\text { lane), Glycerol }\end{array}$ & Hydrothermal synthesis & - & Violet & $9 \pm 0.5$ & {$[70]$} \\
\hline 27. & Citric acid, PEI (polyethyleneimine) & Hydrothermal treatment & - & Blue & 4.5 & {$[56]$} \\
\hline
\end{tabular}


fabricated water soluble Nitrogen-doped CDs using ammonium citrate and ethylenediamine. They heated the aqueous solution of ammonium citrate and ethylenediamine at a constant $200{ }^{\circ} \mathrm{C}$ temperature for $5 \mathrm{~h}$. The average diameter of the N-CDs was found to be $4.8 \mathrm{~nm}$ with a quantum yield of (QY) 66.8\% [54]. Some researchers have also used amino acids as CDs source. Zeng et al. synthesized N, S co-doped CDs (N, S-CDs) having size $\sim 2.6 \mathrm{~nm}$ from $\mathrm{L}$-serine and $\mathrm{L}$-cystine under hydrothermal reaction conditions [55]. Li et al. used citric acid and poly(ethylenimine) (PEI) as raw materials and synthesized CDs with an average diameter of $\sim 4.5 \mathrm{~nm}$ and $48.3 \pm 5.3 \%$ of QY by heating the aqueous solution of citric acid and PEI at $110{ }^{\circ} \mathrm{C}$ for $2 \mathrm{~h}$ [56]. The use of this method to synthesize CDs from small molecules has also been reported by several other researchers $[6,13,38,54$, $55,57-70]$.

\section{Microwave-assisted synthesis}

Microwave assisted synthesis is a fast and low-cost method to synthesize CDs via the irradiation of electromagnetic radiations having a wavelength ranging from $1 \mathrm{~mm}$ to $1 \mathrm{~m}$ through the reaction mixture containing the precursor molecules (Table 3) [71, 72]. Zhu et al. synthesized fluorescent CDs having size $\sim 3.7 \mathrm{~nm}$ using microwave irradiation for the first time. They heated the aqueous solution of saccharides and polyethylene glycol in a domestic microwave oven $(500 \mathrm{~W})$ for nearly $3 \mathrm{~min}$ [73]. Liu et al. synthesized multicolor photoluminescence CDs with an average size of $\sim 5 \mathrm{~nm}$ using glycerol as the carbon source and 4,7,10-trioxa-1,13-tridecanediamine
(TTDDA) as the passivating agent [9]. Wang et al. synthesized water-soluble CDs by one-step microwave assisted pyrolysis of citric acid. They used tryptophan (Trp) as both a passivating agent and nitrogen source. They heated the aqueous solution of citrate and L-Trp in a microwave oven $(700 \mathrm{~W})$ for $3 \mathrm{~min}$, and removed the large particles by centrifugation at 10,000 rpm to get CDs with the size of $\sim 2.6 \mathrm{~nm}$ [74]. Kiran et al. used citric acid as a carbon source and 3-aminophenyl boronic acid as the passivation agent to fabricate CDs. They heated the aqueous solution of citric acid, and 3-aminophenyl boronic acid in a microwave oven $(1200 \mathrm{~W})$ for $4 \mathrm{~min}$ and the average diameter of the obtained CDs was ranging from 2 to $5 \mathrm{~nm}$ [75]. Recently Cao et al. (2018) synthesized CDs from the aqueous solution of glucose and arginine using microwave-assisted pyrolysis in a microwave oven $(700 \mathrm{~W})$ for near about $10 \mathrm{~min}$. The average diameter of the as obtained CDs was between 1 and $7 \mathrm{~nm}$ [76]. Several other researchers have also reported the microwave-assisted the synthesis of CDs [27, 31, 77-81].

\section{Thermal decomposition}

Researchers have also used the thermal decomposition technique as another standard bottom-up method to synthesize CDs (Table 4). In ordinary thermal decomposition, a substance or compound decomposes chemically by the action of heat. Thermal decomposition reactions are generally endothermic. This type of decomposition reactions are either irreversible (decomposition of starch, proteins) or reversible (decomposition of ammonium chloride, limestone). This method offers various

Table 3 Synthesis of CDs from small organic molecules via microwave treatment

\begin{tabular}{|c|c|c|c|c|c|c|}
\hline S. No. & Source & Method of preparation & $\begin{array}{l}\text { Doping }(d) / \\
\text { surface } \\
\text { passivating }(p) \\
\text { agent }\end{array}$ & Color & Size (nm) & Refs. No. \\
\hline 1. & Saccharides and polyethylene glycol & Microwave synthesis & - & Blue & 3.7 & {$[73]$} \\
\hline 2. & Citric acid & Microwave synthesis & Tryptophan (d) & Indigo & 2.6 & {$[74]$} \\
\hline 3. & Glycerol & Microwave synthesis & $\operatorname{TTDA}(p)$ & $\begin{array}{l}\text { Blue, turquoise, green, } \\
\text { jacinth and red }\end{array}$ & 5 & {$[9]$} \\
\hline 4. & Carbohydrates and inorganic salts & Microwave synthesis & - & Blue, green, yellow, red & 2.1 & {$[77]$} \\
\hline 5. & Citric acid & Microwave synthesis & Tryptophan (d) & Indigo & 2.6 & {$[78]$} \\
\hline 6. & Citric acid & Microwave synthesis & RNase A (d) & Blue & $25-45$ & {$[79]$} \\
\hline 7. & Citric acid, urea & Microwave synthesis & Boric acid, $(d)$ & Indigo & $2-6$ & {$[31]$} \\
\hline 8. & Citric acid & Microwave synthesis & $\begin{array}{l}\text { 3-Aminophenyl } \\
\text { boronic acid } \\
\text { (p) }\end{array}$ & Indigo & $2-5$ & {$[75]$} \\
\hline 9. & Citric acid, urea & Microwave-assisted synthesis & - & Green & $2-6$ & {$[27]$} \\
\hline 10. & Triammonium citrate & Microwave irradiation & - & Indigo & 6.5 & {$[80]$} \\
\hline 11. & Glycerol & Microwave pyrolysis & $\operatorname{PEI}(d, p)$ & Blue & $9 \pm 1.1$ & {$[81]$} \\
\hline 12. & Arginine and glucose & Microwave synthesis & - & Blue & $1-7$ & {$[76]$} \\
\hline
\end{tabular}


Table 4 Synthesis of CDs from small organic molecules via thermal decomposition, carbonization, pyrolysis, solvothermal, and ultrasonic treatment

\begin{tabular}{|c|c|c|c|c|c|c|}
\hline S. No. & Source & Method of preparation & $\begin{array}{l}\text { Doping }(d) / \text { surface } \\
\text { passivating }(p) \text { agent }\end{array}$ & Color & Size $(\mathrm{nm})$ & Refs. No. \\
\hline 1. & $\begin{array}{l}\text { Citric acid, } N \text {-( }(\beta \text {-Aminoethyl)- } \\
\text {-aminopropyl methyl } \\
\text { dimethoxy silane }\end{array}$ & Thermal decomposition & AEAPMS (P) & Blue & 0.9 & [82] \\
\hline 2. & Citric acid & Thermal decomposition & $\operatorname{DETA}(p)$ & Blue & $3-5.5$ & [84] \\
\hline 3. & Citric acid & Thermal decomposition & Ruthenium (III) & Blue & $6.8 \pm 2.3$ & [85] \\
\hline 4. & Citric acid & Thermal decomposition & - & Blue & $0.7-1.0$ & [34] \\
\hline 5. & L-Cysteine & Thermal decomposition & $\begin{array}{l}\text { 1-butyl 3-methyl imidazolium } \\
\text { bromide }\end{array}$ & Blue, yellow, red, green & $1.0-3.5$ & [83] \\
\hline 6. & Citric acid & Thermal treatment & Dicyanamide $(d)$ & Green & $8-16$ & [86] \\
\hline 7. & Glucose & Carbonization & $\begin{array}{l}\text { Ethylene diamine }(d) \text {, phos- } \\
\text { phoric acid }(p)\end{array}$ & Green & $1-7$ & [87] \\
\hline 8. & Citric acid & Carbonization & - & Blue & $4.8-9$ & [88] \\
\hline 9. & $\begin{array}{l}\text { 6-O-(O-O-dilauroyl-tartaryl)- } \\
\text { D-glucose }\end{array}$ & Carbonization & - & Green & $2.4 \pm 0.5$ & [89] \\
\hline 10. & Tris base, betaine $\mathrm{Hcl}$ & Pyrolysis & Gadopetetic acid (d) & Purple, Green & 3.2 & [31] \\
\hline 11. & GDs & Pyrolysis & L-glutamic acid & Blue, green and red & $4.66-1.24$ & [17] \\
\hline 12. & D-Glucose & Pyrolysis & L-Aspartic acid (d) & Yellow & $2.28 \pm 0.42$ & [90] \\
\hline 13. & Sodium alginate & Pyrolysis & - & Blue & $<10$ & [91] \\
\hline 14. & Citric acid & Pyrolysis & Diethylenetriamine (p) & Indigo & $5-8$ & [11] \\
\hline 15. & $\mathrm{CCl}_{4}, \mathrm{NaNH}_{2}$ & Solvothermal method & $N(d)$ & Blue, cyan, kelly, and yellow & 3.3 & [36] \\
\hline 16. & $\mathrm{SiCl}_{4}$, hydroquinone & Solvothermal treatment & Si (d) & Blue & $7 \pm 2$ & [29] \\
\hline 17. & hydroquinone & Solvothermal method & $\mathrm{BBr}_{3}(\mathrm{~d})$ & Blue & 16 & [15] \\
\hline 18. & Glucose, $\mathrm{HCl} / \mathrm{NaOH}$ & Ultrasonic treatment & - & Blue & $<5$ & [30] \\
\hline 19. & Active carbon, $\mathrm{H}_{2} \mathrm{O}_{2}$ & Ultrasonic treatment & - & Blue, green, yellow, red & $5-10$ & [92] \\
\hline
\end{tabular}

advantages, such as easy to operate, less time consuming, low cost, and large scale production [45]. Wang et al. synthesized highly luminescent CDs by the thermal decomposition of citric acid as the carbon source and organosilane, $N$-( $\beta$-aminoethyl)- $\gamma$-aminopropyl methyl dimethoxy silane (AEAPMS) as the passivation agent. They heated the reaction mixture at $240{ }^{\circ} \mathrm{C}$ for only $1 \mathrm{~min}$, and the observed diameter of CDs was $\sim 0.9 \mathrm{~nm}$ [82]. Later, Wang et al. synthesized CDs by this method from citric acid. They heated citric acid on a hot plate at $200{ }^{\circ} \mathrm{C}$ for $30 \mathrm{~min}$; neutralized with sodium hydroxide solution, and finally dialyzed for purification. The size of CDs was observed within the range from 0.7 to $1 \mathrm{~nm}$ [34]. These CDs showed both excitation-dependent as well as independent photoluminescent (PL) properties, and different QY depending on different synthesis conditions. Wan et al. used the thermal decomposition of 1-butyl 3-methyl imidazolium bromide and L-cysteine for the synthesis of CDs at $240{ }^{\circ} \mathrm{C}$. AFM study showed that the height of the CDs was ranging from 1.0 to $3.5 \mathrm{~nm}$ [83]. Some other researchers also reported the synthesis of CDs from small organic molecules via this method [84-86].

\section{Carbonization synthesis}

Carbonization of the precursor molecules is one of the best, inexpensive, simple, and ultrafast one-step methods to fabricate CDs (Table 4). Carbonization is a chemical process in which solid residues with higher content of carbon are formed from organic materials by prolonged pyrolysis in an inert atmosphere. Wei et al. synthesized N-doped CDs using this ultrafast carbonization method within 2 min from glucose as a carbon source, and ethylenediamine as the nitrogen source. The observed size of the CDs was in the range of 1 to $7 \mathrm{~nm}$ with $48 \%$ of QY [87]. Wang et al. fabricated blue luminescent thermally-reduced CDs ( $t$-CDs) with size ranging from 4.8 to $9 \mathrm{~nm}$ using citric acid carbonization. They used thermogravimetric analyzer for thermal reduction of CDs, which resulted in the five times increment of QY compared with non-reduced-CDs [88]. Dolai et al. synthesized CDs-aerogel matrix using 6-O-(O-O-dilauroyl-tartaryl)-D-glucose as the carbon source. The observed diameter of nanoparticles was $\sim 2.4 \pm 0.5 \mathrm{~nm}[89]$. 


\section{Pyrolysis synthesis method}

Pyrolysis method for the synthesis of CDs from precursor molecules is also preferred by some researchers (Table 4). Pyrolysis is an irreversible thermal decomposition reaction in which decomposition of organic materials take place in an inert atmosphere. It involves physical as well as chemical changes in organic materials resulting in solid residue containing carbon. Generally pyrolysis takes place at very high temperature and under controlled pressure. Bourlinos et al. synthesized Gd(III)-doped CDs having diameter $\sim 3.2 \mathrm{~nm}$ with dual fluorescence via pyrolysis method. They prepared a mixture of tris(hydroxymethyl) aminomethane (Tris base), gadopentetic acid, and betaine hydrochloride to fabricate $\mathrm{Gd}(\mathrm{III})$-CDs followed by the pyrolysis at $250{ }^{\circ} \mathrm{C}$ temperature [31]. Zheng et al. synthesized a new type of CDs using L-aspartic acid and D-glucose as source molecules via a straight forward pyrolysis method. They prepared the solution of L-aspartic acid and D-glucose in aqueous $\mathrm{NaOH}$ and heated it at $200{ }^{\circ} \mathrm{C}$ for $20 \mathrm{~min}$. The observed average diameter of CDs was $2.28 \pm 0.42 \mathrm{~nm}$ [90]. Feng et al. synthesized CDs from citric acid via thermal pyrolysis method. They used diethylenetriamine as the passivation agent, and according to TEM results, the size of CDs was ranging from 5 to $8 \mathrm{~nm}[11]$.

\section{Solvothermal method}

There are some reports where researchers used solvothermal method for the synthesis of CDs from small organic molecules as the carbon source (Table 4). For example, Zhang et al. (2012) synthesized N-doped CDs through the solvothermal route using $\mathrm{CCl}_{4}$ as carbon and $\mathrm{NaNH}_{2}$ as a nitrogen source. The as-prepared CDs were crystalline and had graphite-like structure with an average size of $3.3 \mathrm{~nm}$ and height ranging from 0.5 to $5 \mathrm{~nm}$ [36]. Qian et al. synthesized Si-doped CDs via this method using $\mathrm{SiCl}_{4}$ and hydroquinone. They heated the mixture of $\mathrm{SiCl}_{4}$ and hydroquinone in acetone within a stainless steel autoclave at $200{ }^{\circ} \mathrm{C}$ for $2 \mathrm{~h}$. The observed diameter of the Si-doped CDs was $7 \pm 2 \mathrm{~nm}$ [29]. Shan et al. used one-pot solvothermal method for the synthesis of Boron-doped CDs. They used hydroquinone as the precursor of carbon and $\mathrm{BBr}_{3}$ as the source of boron. The average size of the as-prepared B-doped CDs was $\sim 16 \mathrm{~nm}$ [15].

\section{Ultrasonic treatment}

There are limited numbers of studies, where researchers used ultrasonic treatment method to synthesize CDs (Table 4). For example, Li et al. [30] synthesized watersoluble fluorescent CDs having a size in the range of 5-10 $\mathrm{nm}$ through the acid assisted ultrasonic treatment of glucose. In the same year, $\mathrm{Li}$ et al. synthesized watersoluble fluorescent CDs from activated carbon using one-step $\mathrm{H}_{2} \mathrm{O}_{2}$ assisted ultrasonic treatment method. According to the TEM results, the average size of CDs was ranging from 5 to $10 \mathrm{~nm}$, and the surface of CDs was rich in hydroxyl groups [30, 92].

\section{Applications of CDs Bioimaging}

CDs are considered as a potential candidate for bioimaging application due to its unique fluorescent nature, high photobleaching resistivity, less cytotoxicity, and better aqueous solubility (Fig. 2 and Table 5) [40, 93]. In the beginning, Ray et al. prepared the water-soluble, blue and yellow fluorescent CDs from carbon soot and nitric acid. The as-prepared CDs entered into the HepG2 cells and used for bio-imaging [40]. Qiao et al. used TTDDA (4,7,10-trioxa-1,13-tridecanediamine) passivated CDs for imaging of COS-7 cells [94]. After that Zhu et al. (2011) synthesized highly fluorescent graphene dots (GDs) via a one-step solvothermal route from graphene oxide for excitation-dependent fluorescent bioimaging of MG-63 cells [93]. Wang et al. fabricated biocompatible CDs/silica (silica-encapsulated CDs) nanoparticles having a size of $12 \mathrm{~nm}$ via decomposition pyrolysis method and applied them for bioimaging of BGC823 cells [82]. Yang et al. used glucose derived green florescent CDs as the bioimaging agent for labeling HepG2 cells. They also studied the intracellular localization of the CDs via counterstaining with 40,6-diamidino-2-phenylindole (DAPI). They showed cytoplasmic localization of the CDs surrounding the nucleus [52]. Peng et al. prepared water-soluble florescent CDs of carbon fibers for bioimaging of breast T47D cancer cells [95]. Carbon nanotubes and graphite derived yellow fluorescent CDs was used by Tao et al. for in vivo bioimaging and labeling purposes. A nude mouse was injected with CDs-M (CDs made from MWNTs) at three regions on its back-side intravenously, and the images were taken by the Maestro optical imaging system. They observed that the CDs were mainly accumulated within the liver and spleen. However, after short term exposure CDs were mainly accumulated within the kidney, indicating the urinary clearance of the CDs [3]. Zhang et al. used electrochemical method for synthesizing yellow fluorescent CDs with a diameter of 5 to $10 \mathrm{~nm}$ from graphite rods followed by reduction with hydrazine and applied for bioimaging of human lung A549 and breast MCF-7 carcinoma cells [96]. Dong et al. used CDs $(15 \mathrm{~nm})$ obtained via chemical oxidation of XC-72 carbon black for labeling MCF-7 breast cancer cells [97]. In the same year (2012) some other researchers also synthesized fluorescent CDs for bioimaging and labeling purposes [9, 


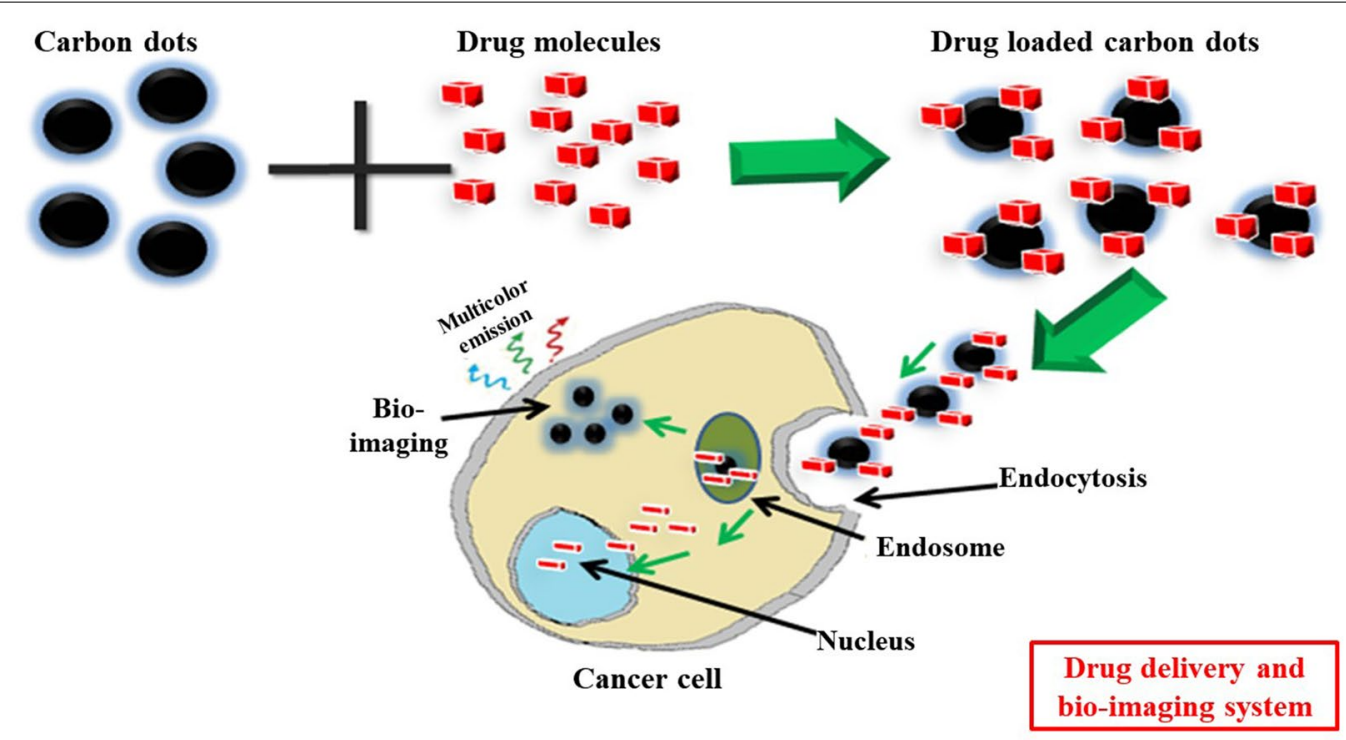

Fig. 2 General mechanism of image guided drug delivery via CDs: drug loaded CDs enter into the cells, and deliver the drug to nucleus. Also, the intrinsic multicolor fluorescence nature of CDs helps in tracking the drug delivery pathway, and cellular imaging

57, 98-100]. After that in 2013 Pan et al. fabricated CDs for imaging HeLa cell. The CDs (3 nm) were fabricated using thermal reduction of the mono-layer graphene oxide sheets in the presence of $\mathrm{H}_{2} \mathrm{SO}_{4}$ and $\mathrm{HNO}_{3}$. They demonstrated that the CDs-labeled Hela cells did not exhibit any reduction in PL during continuous excitation, indicating that CDs could be a potential substitute of dyes [101]. Zhu et al. used citric-acid, and ethylenediamine derived CDs for imaging MC3T3 cells [39]. A large scale synthesis of CDs from sucrose was reported by Chen et al. [102]. The as-prepared CDs were applied for $16 \mathrm{HBE}$ cells imaging at $488 \mathrm{~nm}$ [102]. After that $\mathrm{Hu}$ et al. synthesized blue luminescent $\mathrm{N}$-doped CDs by hydrothermal treatment method for HeLa cells imaging. The CDs did not show any significant toxicity to the cells and were mostly localized in the cytoplasmic region [103]. Likewise, CDs synthesized from several other sources, like graphene oxide and DMF, Polycyclic aromatic hydrocarbon as well as graphite powder were also reported for in vitro cell imaging [104-106]. Folic acid based N-doped CDs were used by Wang et al. for imaging U87 glioma cells [107]. Polythiophene phenyl propionic acid derived red-emissive CDs were synthesized by Ge et al. [108], and used for both in vitro and in vivo imaging. For in vitro bioimaging, HeLa cells were treated with the CDs which showed red fluorescence localized in the cytoplasm when excited at $543 \mathrm{~nm}$. They also intravenously injected CDs in the HeLa-tumor bearing mice and observed that the CDs were mostly accumulated inside the tumor due to enhanced permeation and retention (EPR) effect. Based upon their results, they concluded that the as-synthesized CDs could be applied for both fluorescent imaging as well as photoacoustic imaging agent [108]. In the same year, Krishna et al. used citric acid, PEG diamine, and glycerin to synthesize CDs and functionalize them with digitonin for cholesterol detection and imaging [109]. A mixture of phosphoric acid, citric acid, and ethylenediamine was used by Parvin et al. to synthesized N, P co-doped CDs via hydrothermal treatment and used for bioimaging of RAW 264.7 cells [110]. Borse et al. used urea, and polyethylene glycol (PEG) derived CDs for bioimaging in $\mathrm{L} 929$ cells. The CDs were localized in the cell cytoplasm and showed excitation-dependent multicolor emission [111]. Yang et al. fabricated F-doped CDs from the mixture of citric acid, sodium fluoride and urea, and used for imaging in both in vivo and in vitro models. They observed that CDs showed red fluorescence in the cytoplasm of glioma C6 cells when excited at $530 \mathrm{~nm}$. In case of in vivo imaging, they injected CDs in the nude mice bearing xenograft tumor and checked the whole body fluorescence at an excitation wavelength of $530 \mathrm{~nm}$ and an emission wavelength of $600 \mathrm{~nm}$. It was observed that the CDs were mostly accumulated within the tumor region due to the EPR effect [112].

\section{Drug/gene delivery}

CDs can be used as a vehicle for drug/gene delivery due to their synthesis from cheap sources, facile surface functionalization, tiny size, and higher biocompatibility (Table 6). Besides, the drug/gene delivery pathway is also tracked due to the intrinsic fluorescence nature of $\mathrm{CD}$; therefore considered as an excellent alternative 
Table 5 Role of CDs in bioimaging application

\begin{tabular}{|c|c|c|c|c|}
\hline S. No. & Source molecule & Color & Application (bio-imaging) & Refs. No. \\
\hline 1. & Carbon soot & Blue-yellow & HepG2 cell & [40] \\
\hline 2. & Activated carbon & Blue/yellow/green & cos-7 cells & [94] \\
\hline 3. & Graphene oxide and DMF & Green & MG-63 cell & [93] \\
\hline 4. & Citric acid, AEAPMS and silica & Blue & BGC823 cell & [82] \\
\hline 5. & Glucose, monopotassium phosphate & Green & HepG2 cell & [52] \\
\hline 6. & Carbon fibers & Green & T47D Cell & [95] \\
\hline 7. & Carbon nanotubes and graphite & Yellow & In vivo NIR fluorescence imaging in mice & [3] \\
\hline 8. & Graphite rods and hydrazine & Yellow & $\begin{array}{l}\text { Neurospheres cells, pancreas progenitor cells, and } \\
\text { cardiac progenitor cells were performed }\end{array}$ & [96] \\
\hline 9. & CX-72 carbon black & Green & MCF-7 cell & [97] \\
\hline 10. & Glycerol, Polyethylenimine (PEI) & Blue/green/red & cos-7 cell & [9] \\
\hline 11. & Glycine & Green & MCF-10A, MCF-7 cells & [98] \\
\hline 12. & Glucose and TTDDA & Green & HeLa, MCF-7, NIH-3T3 cells & [99] \\
\hline 13. & Glycerol solvent & Blue & HeLa cell & {$[100]$} \\
\hline 14. & Graphene oxide and ammonia & Green & HELA cell & [101] \\
\hline 15. & Citric acid and ethylenediamine & Blue & MC3T3 cell & [39] \\
\hline 16. & Sucrose and oil acid & Green & $16 \mathrm{HBE}$ cell & [102] \\
\hline 17. & Graphene oxide and ammonia & Blue & HeLa cell & [103] \\
\hline 18. & Graphene oxide and Dimethylformamide & Green & HeLa cell & [104] \\
\hline 19. & Polycyclic aromatic hydrocarbon & Green & MCF-7 cell & [105] \\
\hline 20. & Graphite powder & Green/blue & A549 cell & {$[106]$} \\
\hline 21. & Folic acid & Blue, Green & U87 glioma cell & [107] \\
\hline 22. & Polythiophene phenyl propionic acid & Red & HeLa cell imaging and diagnosis & [108] \\
\hline 23. & Citric acid, PEG diamine, and Glycerin & Blue & Cholesterol imaging & [109] \\
\hline 24. & Citric acid, phosphoric acid, and ethylene diamine & Red, green & RAW 264.7 cells, PA and FL imaging of mice tumors & [110] \\
\hline 25. & Urea, polyethylene glycol (PEG) & Blue & L929 cells & [111] \\
\hline 26. & Citric acid, urea and sodium fluoride & Red & Glioma C6 cells & [112] \\
\hline
\end{tabular}

to other fluorescent dyes or semiconductor nanoparticles (Figs. 2, 3) [113]. In order to deliver the anticancer drug, doxorubicin (DOX) into cancer cells, Zhou et al. used fluorescent $\mathrm{CD}$-gated mesoporous silica nanoparticles (MSPs) as a pH-responsive drug carrier and bioimaging system. The as-prepared CDs@MSPs were biocompatible and showed strong fluoresce both in vitro and in vivo. DOX-loaded CDs@MSPs entered into cancer cells via endocytosis, showed a $\mathrm{pH}$-responsive drug release behavior in mildly acidic condition and enhanced cytotoxicity in Hela cells [114]. After that Yang et al. fabricated $\beta$-cyclodextrin $(\beta C D)$, oligoethylenimine (OEI) and Phosphoric acid based green luminescent CDs for a drug delivery system. They further functionalize CDs with HA (hyaluronic acid) for active targeting onto tumor cells. The nanoparticles were noncytotoxic and exhibited green fluorescence in H1299 cells. They also demonstrated that DOX-loaded CD nanocomplexes exhibited higher cytotoxicity towards H1299 cells than that of free DOX [115]. Wang et al. used CDs/DOX nanocomplexes as the image-guided drug delivery system. They synthesized the CDs form citric acid and o-phenylenediamine, and the positively charged DOX was loaded on the surface of negatively charged CDs through electrostatic interactions. However, the fluorescence of CDs decreased after loading with DOX, while after the release of DOX from the surface of CDs, fluorescence was regained and thereby acted as an image-guided drug delivery system [116]. Further, the CDs/DOX nanocomplexes showed higher cytotoxicity towards cancerous cells (HeLa) compared with normal cells (L929, mouse fibroblast cells).

Recently Kong et al. fabricated a citric acid and ethylenediamine based CDs for drug delivery systems. According to their results they observed that DOX could be quickly loaded on CDs through electrostatic interaction and the CDs/DOX complexes showed better cellular uptake and antitumor efficiency on the breast cancer MCF-7 cells compared with free DOX [117]. Similarly, some other researchers have also used CDs loaded with DOX for simultaneous cell imaging and drug delivery systems [27, 114, 118-120]. Zheng 
Table 6 Role of CDs in drug/gene delivery system

\begin{tabular}{|c|c|c|c|c|c|}
\hline S. No. & Source molecule & Ligand attached & Drug/gene delivery & Cell type & Refs. No. \\
\hline 1. & EDTA & $\begin{array}{l}\text { Mesoporous silica nanoparticles } \\
\text { (MSPs) }\end{array}$ & DOX & HeLa & [114] \\
\hline 2. & Sorbitol and sodium hydroxide & Folic acid & DOX & HeLa & [118] \\
\hline 3. & $\begin{array}{l}\beta \text {-Cyclodextrin ( } \beta C D) \text {, oligoethyl- } \\
\text { enimine (OEI) and Phosphoric } \\
\text { acid }\end{array}$ & OEI/CD & DOX & H1299 & [115] \\
\hline 4. & $\begin{array}{l}\text { citric acid and o-phenylenedi- } \\
\text { amine }\end{array}$ & - & DOX & HeLa, mouse fibroblast cells (L929) & [116] \\
\hline 5. & Carbon nanopowder & Transferrin & DOX & $\begin{array}{l}\text { Glioblastoma cells; CHLA-266, } \\
\text { DAOY, CHLA-200 and SJGBM2 } \\
\text { cells }\end{array}$ & [119] \\
\hline 6. & Urea and citric acid & carboxyl groups on CDs & DOX & HepG2 and HL-7702 & [27] \\
\hline 7. & $\begin{array}{l}\text { ATP (Adenosine Triphosphate) } \\
\text { moreover, polyethyleneimine } \\
\text { (PEI) }\end{array}$ & Hyaluronic acid (HA) & DOX & HeLa cells & [120] \\
\hline 8. & $\begin{array}{l}\text { D-Glucose }(2.5 \mathrm{mmol}) \text { and } \\
\text { L-glutamic acid }\end{array}$ & Polydopamine coated & DOX & HeLa & [121] \\
\hline 9. & $\begin{array}{l}\text { Citric acid and polyene polyamine } \\
\text { (PEPA) }\end{array}$ & & Oxaliplatin & Hepatic cancer cells & [122] \\
\hline 10. & Citric acid and ethylenediamine & - & DOX & L929, MCF-7 and CCK-8 & [117] \\
\hline 11. & Citric acid and diethylenetriamine & PEG-(PAH/DMM) & Cisplatin & A2780 & [11] \\
\hline 12. & $\begin{array}{l}\text { Glycerol and polyethylenimine } \\
\text { (PEI) }\end{array}$ & $\begin{array}{l}\text { fc-rPEI (folate conjugated reducible } \\
\text { PEI rPEI) }\end{array}$ & siRNA & $\mathrm{H} 460$ & [123] \\
\hline 13. & Citric acid and tryptophan & PEl & siRNA & MGC-803 & [60] \\
\hline 14. & $\begin{array}{l}\text { Branched polyethyleneimine, } \\
\text { Hyaluronic acid }\end{array}$ & $\begin{array}{l}\text { Hyaluronate (HA) and polyethyl- } \\
\text { eneimine (PEI) functionalized }\end{array}$ & DNA/RNA & Hela cells & [124] \\
\hline 15. & $\begin{array}{l}\text { Polyethyleneimine and fluorinated } \\
\text { diglycidyl ethers }\end{array}$ & Fluorine doped & siRNA/DNA & 7702, A549 and HepG2 & [125] \\
\hline 16. & Arginine and glucose & - & pSOX-9 & $\begin{array}{l}\text { Chondrogenic differentiation of } \\
\text { mouse embryonic } \\
\text { Fibroblasts }\end{array}$ & [76] \\
\hline
\end{tabular}

et al. fabricated fluorescent CDs with an anticancer drug, oxaliplatin (CD-Oxa) via condensation reaction between the carboxyl groups of oxaliplatin derivative and the amino groups on the CD surface to increase its anticancer efficacy. They demonstrated that the assynthesized CD-Oxa could enter into hepatic cancer cells and release the active drug under reducing environment. They also showed that the CDs were biocompatible towards normal fibroblast cells, whereas the CD-Oxa was cytotoxic towards hepatic cancer cells. They used the CDs and CD-Oxa as image guided drug delivery system for both in vitro and in vivo applications. They took hepatic cancer cells zenograft tumor mice model and found that intra-tumoral injection of the CD-Oxa effectively killed tumor cells and decreased the tumor volume with less systemic toxicity [122]. Later, Feng et al. used cisplatin (IV) pro-drug-loaded charge convertible CDs [CDs-Pt(IV)@PEG-(PAH/ DMMA)] for image-guided drug delivery based upon the citric acid and diethylenetriamine as the precursor's molecules.
The charge convertible CDs were obtained via further functionalizing the CDs with PEG-poly(allylamine) and polydimethylmaleic acid (PEG-(PAH/DMMA). From the in vitro experiments, they demonstrated that the charge convertible nano-carriers offer higher therapeutic capability in the tumor extracellular environment compared with normal physiological conditions. Besides, they also used zenograft tumor bearing mice model and found that intravenous injection of the nanoformulations exhibited better tumor cells inhibition capability with less systemic toxicity [11].

Wang et al. fabricated CDs based upon citric acid and tryptophan (as passivation agent) for imaging-guided survivin siRNA delivery in the gastric cancer cells. The as-prepared CDs were further coated with PEI which binds the negatively charged siRNA. The western blot and qRT-PCR experiments assured the survivin gene silencing via nanoparticle-mediated siRNA delivery into the MGC-803 cells. They also showed the secondary effects of survivin gene silencing in the MGC-803 


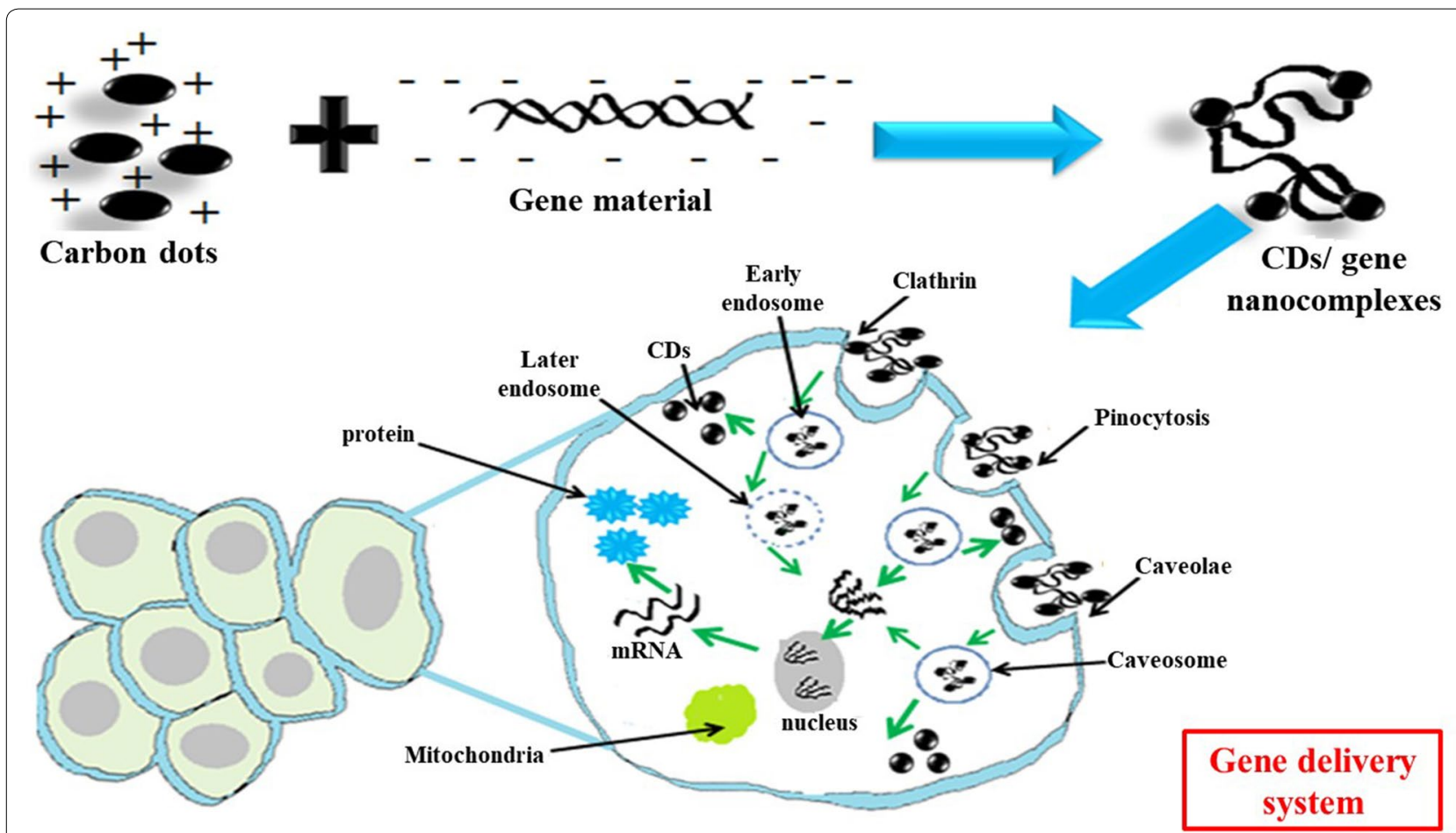

Fig. 3 General mechanisms of gene delivery via CDs: here CDs bind with gene materials via electrostatic interactions, enter into the cells via endocytosis and release the payloads into nucleus

cells, such as cell cycle arrest at the G1 phase and enhanced apoptosis [60].

$\mathrm{Wu}$ et al. used folate-conjugated reduction-sensitive polyethyleneimine passivated CDs for targeted EGFR and cyclinB1 siRNA delivery and targeting in $\mathrm{H} 460$ lung cancer cells. The combined siRNAs were released in reducing intracellular conditions and increased the anti-cancer activity in H460 cells [123]. Recently Cao et al. fabricated dual functional cationic CDs from glucose and arginine for imaging and SOX9 plasmid delivery in mouse embryonic fibroblasts (MEFs). They observed that CDs/pSOX9 nano-particles possessed low cytotoxicity towards MEFs, helped in the intracellular tracking, and SOX9-dependent chondrogenic differentiation [76]. Several other researchers have also worked with CDs, as non-viral gene delivery vectors $[124,125]$.

\section{Bio-sensing}

CDs have also been employed by researchers as a biosensing and chemical-sensing nano-materials due to their unique properties like excitation-dependent emission, higher photostability, low cytotoxicity and better aqueous solubility (Table 7) [45]. The changes in their fluorescence property take place via different mechanisms, such as resonance energy transfer, inner filter effect, photo-induced electron and charge transfer [126]. These nanomaterials can be used for sensing of several biological molecules and intracellular metal ions, such of $\mathrm{H}_{2} \mathrm{O}_{2}, \mathrm{Fe}^{3+}, \mathrm{C}_{6} \mathrm{H}_{12} \mathrm{O}_{6}$, Vitamin $\mathrm{B}_{12}$, L-cysteine, galactose, etc. via changing their fluorescence intensity (Fig. 4). Wu et al. used L-glutamic acid derived CDs for effective detection of $\mathrm{H}_{2} \mathrm{O}_{2}$. The asprepared $\mathrm{CDs}$ possessed peroxidase-like activity which was utilized for $\mathrm{H}_{2} \mathrm{O}_{2}$ detection in the presence of 2 , $2^{1}$-azino-bis(3-ethylbenzothiazoline-6-sulphonic acid (ABTS) with the detection limit of $20 \mu \mathrm{M}$ [17].

Qian et al. used hydroquinone, and $\mathrm{SiCl}_{4}$ derived CDs as the sensor for $\mathrm{Fe}^{3+}, \mathrm{H}_{2} \mathrm{O}_{2}$, and melamine. The detection of $\mathrm{H}_{2} \mathrm{O}_{2}$ was attained by an electron transfer mechanism between Si-doped $\mathrm{CDs}$ and $\mathrm{H}_{2} \mathrm{O}_{2}$, while both electron and energy transfer mechanisms were operating for detecting $\mathrm{Fe}^{3+}$. Formation of a stable adduct between $\mathrm{H}_{2} \mathrm{O}_{2}$ and melamine following melamine addition recovered the fluorescence and thereby acted as a sensitive detector for melamine as well [29]. Similarly, Shan et al. used B-doped CDs for selective detection of $\mathrm{H}_{2} \mathrm{O}_{2}$, and the detection limit was $10.0 \mathrm{mM}$. The same CDs could also be used for detection of glucose in the presence of glucose oxidase which produces $\mathrm{H}_{2} \mathrm{O}_{2}$ via oxidation of glucose [15]. Jiang et al. synthesized Si-CDs@ DA (dopamine) via microwave-assisted method for the intracellular $\mathrm{Ag}^{+}$detection via fluorescence quenching 
Table 7 Role of CDs in bio-sensing application

\begin{tabular}{|c|c|c|c|c|}
\hline S. No. & Precursor molecule & Color & Application (bio-sensing) & Refs. No. \\
\hline 1. & L-Glutamic acid & Blue, green and red & $\mathrm{H}_{2} \mathrm{O}_{2}$ & {$[17]$} \\
\hline 2. & $\mathrm{SiCl}_{4}$, hydroquinone & Blue & $\mathrm{Fe}^{3+}, \mathrm{H}_{2} \mathrm{O}_{2}$, and melamine & [29] \\
\hline 3. & $\mathrm{BBr}_{3}$, hydroquinone & Blue & $\mathrm{H}_{2} \mathrm{O}_{2}$ and glucose & [15] \\
\hline 4. & $\begin{array}{l}\text { Dopamine and (3-aminopropyl) triethox- } \\
\text { ysilane, glycerol }\end{array}$ & Blue & $\mathrm{Ag}^{+}$ & {$[127]$} \\
\hline 5. & Oxalic acid $(\mathrm{OA})$ and urea & Blue & $\mathrm{Fe}^{3+}$ and $\mathrm{Ag}^{+}$ & [128] \\
\hline 6. & Fullerenes (C60) & Blue & $\mathrm{Fe}^{3+}$ & [130] \\
\hline 7. & Lactose and $\mathrm{NaOH}$ & Blue & Folic acid & [129] \\
\hline 8. & $\begin{array}{l}\text { Galactose and } m \text {-aminophenyl boronic } \\
\text { acid }\end{array}$ & Blue & Galactose & [131] \\
\hline 9. & Citric acid, aminoguanidine & Blue & Nitric oxide (NO) & [132] \\
\hline 10. & Citric acid and melamine & Blue & Glutathione & [134] \\
\hline
\end{tabular}

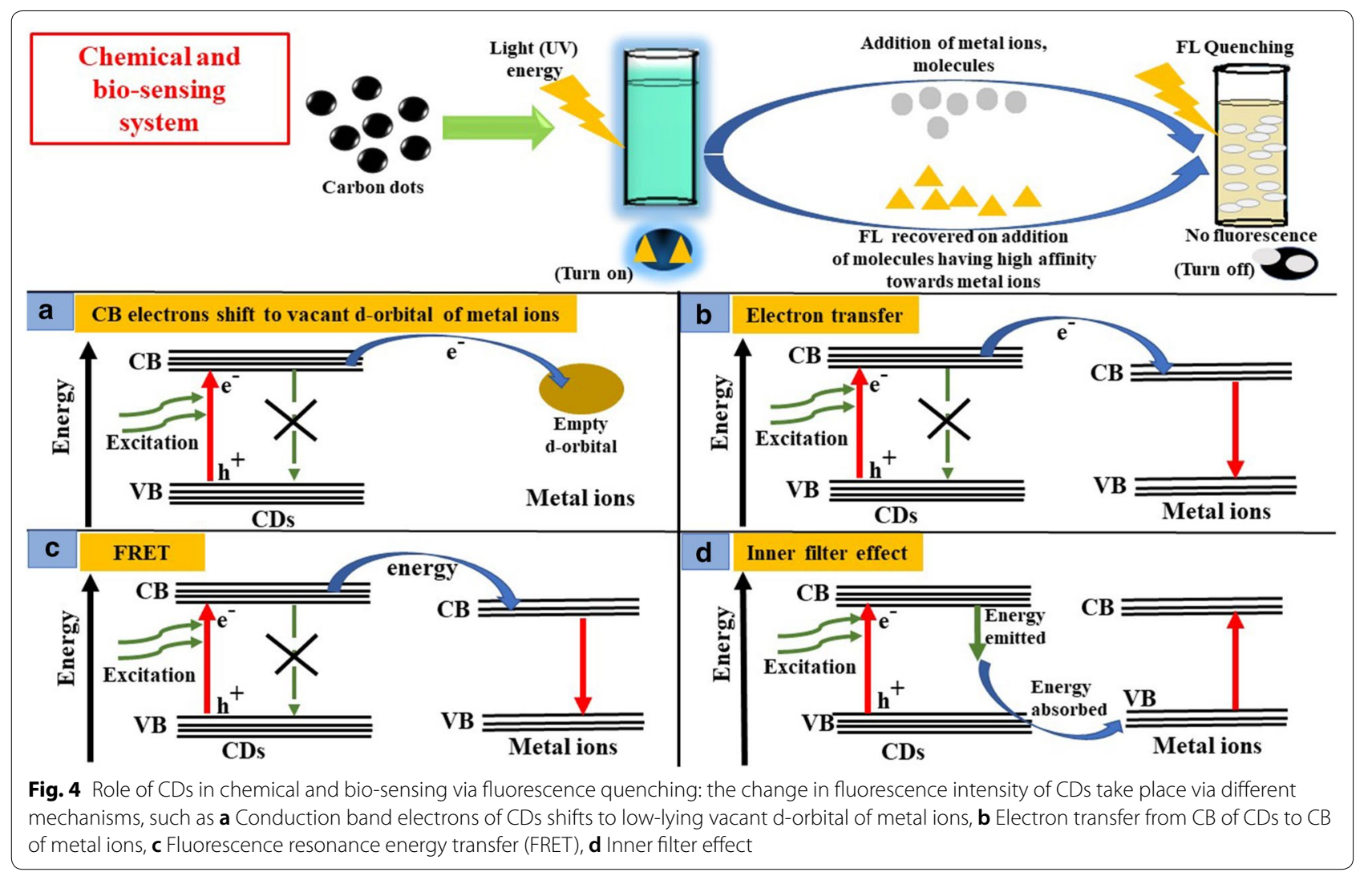

with the linear sensing range of 5 to $50 \mathrm{nM}$ and detection limit of $2.5 \mathrm{nM}$ [127]. In the same year, Lu et al. used water-soluble CDs obtained from oxalic acid (OA) and urea for effective detection of $\mathrm{Fe}^{3+}$ and $\mathrm{Ag}^{+}$in biosystem. The CDs were capable of sensing $\mathrm{Fe}^{3+}$ with a linear range of 1.0 to $130 \mu \mathrm{M}$ and $\mathrm{Ag}^{+}$with a linear range of 0.50 to $200 \mu \mathrm{M}$ [128]. Chen et al. fabricated fluorescent $\mathrm{CDs}$ from lactose and $\mathrm{NaOH}$ by simple heating. They observed that folic acid could quench the fluorescence of the as-prepared CDs upon binding and employed those CDs as the selective probe for folic acid detection in the human urine [129]. The detection of $\mathrm{Fe}^{3+}$ using fullerene (C60) derived CDs was demonstrated by Lan et al. [130]. They passivated the CD surface with hydroxyl and carboxyl groups which interact with $\mathrm{Fe}^{3+}$, thereby quenching the fluorescence [130]. Yang et al. introduced boronic 
Table 8 Role of CDs in chemicals sensing application

\begin{tabular}{|c|c|c|c|}
\hline S. No. & Precursor molecule & Application (chemical-sensing) & Refs. No. \\
\hline 1. & Ethylenediaminetetra acetic acid (EDTA) & $\mathrm{Hg} 2+$ & [134] \\
\hline 2. & Sodium citrate and citric acid & $\mathrm{Hg}^{2+}$ & [13] \\
\hline 3. & Ammonium citrate and ethylenediamine & $\mathrm{Hg}^{2+}$ & [54] \\
\hline 4. & Citric acid, $\mathrm{NH}_{3} \cdot \mathrm{H}_{2} \mathrm{O}$ & $\mathrm{Hg}^{2+}$ & {$[6]$} \\
\hline 5. & Sodium citrate and citric acid & $\mathrm{Hg}^{2+}$ & [135] \\
\hline 6. & Phenolphthalein and ethylenediamine & $\mathrm{Hg}^{2+}$, lemon yellow dye, $\mathrm{Fe}^{2+}$ and $\mathrm{H}_{2} \mathrm{O}_{2}$ & [136] \\
\hline 7. & Citric acid and triethylamine & $\mathrm{Hg}^{2+}$ & [137] \\
\hline 8. & o-Phenylenediamine & $\mathrm{pH}, \mathrm{Hg}^{2+}, \mathrm{Cl}^{-}$and $\mathrm{Cr}^{4+}$ & [138] \\
\hline 9. & Graphite rods & $\mathrm{Fe}^{3+}$ & [139] \\
\hline 10. & Polycyclic aromatic hydrocarbon (PAH) & $\mathrm{Fe}^{3+}$ & [105] \\
\hline 11. & Ethylene glycol & $\mathrm{Fe}^{3+}$ & [143] \\
\hline 12. & Citric acid & $\mathrm{Fe}^{3+}$ & [144] \\
\hline 13. & Citric, thiourea & $\mathrm{Fe}^{3+}$ & {$[145]$} \\
\hline 14. & Cetylpyridinium bromide (CPB) & $\mathrm{Fe}^{2+}$ & {$[140]$} \\
\hline 15. & Folic acid and 3-aminopropyl trimethoxy silane & $\mathrm{Fe}^{3+}$ & [141] \\
\hline 16. & Phenylenediamine & $\mathrm{Fe}^{3+}$ & {$[142]$} \\
\hline 17. & Citric acid & $\mathrm{Fe}^{3+}$ and $\mathrm{I}^{-}$ & [155] \\
\hline 18. & D-Sorbitol & $\mathrm{Fe}^{3+}$ & [156] \\
\hline 19. & $\mathrm{CCl}_{4}$ as a carbon and diamines as nitrogen precursors & $\mathrm{Ag}+$ & [146] \\
\hline 20. & Uric acid & $\mathrm{Ag}^{+}$and $\mathrm{Hg}^{2+}$ & [147] \\
\hline 21. & 1,2-diaminobenzene & $\mathrm{Ag}^{+}$ & [148] \\
\hline 22. & Citric acid and amino acid & $\mathrm{Ag}^{+}$ & [149] \\
\hline 23. & uric acids & $\mathrm{Ag}^{+}$ & [150] \\
\hline 24. & Citric acid and guanidine thiocyanate & $\mathrm{Ag}^{+}$ & [151] \\
\hline 25. & Urea, polyethylene glycol (PEG) & $\mathrm{Ag}+$ & [111] \\
\hline 26. & Citric acid, poly(ethylenimine) for BPEI-CQDs & $\mathrm{Cu}^{2+}$ & {$[12]$} \\
\hline 27. & Ammonium citrate and ethylenediamine & $1^{-}$ & [54] \\
\hline 28. & Sodium alginate & Ascorbic acid & [91] \\
\hline 29. & Ascorbic acid and glycol & $\mathrm{Al}^{3+}$ and $\mathrm{F}^{-}$ & [152] \\
\hline 30. & Citric acid & Selenite $\left(\mathrm{SeO}_{3}{ }^{2-}\right)$ & [153] \\
\hline 31. & Citric acid, and 1,6-diaminohexane dihydrochloride & $\mathrm{Cr}^{6+}$ & [154] \\
\hline
\end{tabular}

acid functionalized CDs as the biosensor nanomaterials for detecting galactose. The boronic acid moiety present on the CD surface reacted with cis-diol units of galactose to give rise cyclic boronate esters, leading to quenching and selective detection of galactose in human urine [131]. Bhattacharya et al. also used aminoguanidine based CDs for nitric oxide (NO) detection via formation of azo dye [132]. Recently Iqbal et al. fabricated N-doped CDs from citric acid and melamine (passivation agent) and applied them for sensing glutathione and $\mathrm{Hg}^{2+}$ in the biological system via fluorescence quenching [133].

\section{Chemical-sensing}

The interaction of metal ions and surface functional groups of CDs lead to the formation of new electronhole recombination, with the help of energy transfer route and results in the change of the fluorescence nature of CDs (Fig. 4). This property of CDs is utilized for sensing different types of metal ions [7], such as $\mathrm{Hg}^{2+}$ [134], $\mathrm{Ag}^{+}$[146], $\mathrm{Cu}^{2+}$ [12], $\mathrm{Fe}^{3+}$ [142] etc. (Table 8).

The heavy metal ion, $\mathrm{Hg}^{2+}$ is highly toxic, and CDs are employed for $\mathrm{Hg}^{2+}$ detection on several occasions. Zhou et al. demonstrated the use of unmodified CDs for the detection of $\mathrm{Hg}^{2+}$ and biothiols (glutathione, cysteine, and homocysteine) with higher selectivity and sensitivity. They observed that the addition of $\mathrm{Hg}^{2+}$ to $\mathrm{CDs}$ caused fluorescence quenching. However, subsequent addition of biothiols to the $\mathrm{Hg}^{2+} / \mathrm{CDs}$ recovered the fluorescence via the removal of $\mathrm{Hg}^{2+}$ ions which has a high affinity towards thiol (-SH) groups [134]. After that Guo et al. synthesized CDs from sodium citrate/citric acid via hydrothermal treatment for the selective and sensitive detection of $\mathrm{Hg}^{2+}$ ions [13]. 
Similarly Li et al. and Zhang et al. fabricated $\mathrm{N}$ doped CDs and applied them for effective detection of mercury ions $[6,54]$. Later, $\mathrm{Xu}$ et al. demonstrated the use of blue fluorescent Mn-doped CDs for the highly selective and sensitive detection of $\mathrm{Hg}^{2+}$ ions via fluorescence quenching with a $\mathrm{nM}$ detection limit due to its higher chemical affinity towards $\mathrm{Hg}^{2+}$ ions compared with various other metal ions. The fluorescence quenching by $\mathrm{Hg}^{2+}$ might be due to the electron transfer or energy transfer from CDs [135]. Pan at el. fabricated green fluorescent CDs from phenolphthalein and ethylenediamine for multimode sensing. They observed that the fluorescence emission of CDs was selectively quenched by $\mathrm{Hg}^{2+}$ ions (with detection limit $5.8 \mu \mathrm{M}$ ) due to the photo induced electron transfer mechanism between them. Furthermore, CDs exhibited significant fluorescent response to lemon yellow dye, $\mathrm{H}_{2} \mathrm{O}_{2}$ and $\mathrm{Fe}^{2+}$ with detection limits of 0.5 , 1.1 and $1.2 \mu \mathrm{M}$ respectively [136]. Wang et al. synthesized N-doped CDs from citric acid and triethylamine via hydrothermal treatment for rapid and selective detection of $\mathrm{Hg}^{2+}$ ions. They observed that the $\mathrm{N}$-doped CDs could act as highly sensitive sensor to $\mathrm{Hg}^{2+}$ ions in tap water samples, with a detection limit of $2.8 \mathrm{nM}$ [137]. Recently Li et al. fabricated blue/yellow emissive CDs from o-phenylenediamine as the multi-mode sensor materials and applied for the selective detection of $\mathrm{Hg}^{2+}, \mathrm{Cl}^{-}$and $\mathrm{Cr}^{4+}$ ions. They observed that blue emission of CDs get quenched by $\mathrm{Hg}^{2+}$ (turn off) and recovered on addition of $\mathrm{Cl}^{-}$ions (turn on). Furthermore, blue/yellow fluorescence of CDs get quenched significantly on addition of $\mathrm{Cr}^{4+}$ ions [138]. Zhang et al. synthesized graphitic CDs as fluorescent material for selective and sensitive detection of the $\mathrm{Fe}^{3+}$ ions. They observed that the hydroxyl and carboxyl groups present on the surfaces of CDs help in interaction with $\mathrm{Fe}^{3+}$ ions and thereby enabling $\mathrm{CDs}$ to act as the fluorescence sensor for detecting $\mathrm{Fe}^{3+}$ ions with a detection limit of $2 \mathrm{nM}$ [139]. Recently the detection of $\mathrm{Fe}^{2+}$ with the help of CDs based upon cetyl pyridinium bromide as the source molecule was reported by Kaur et al. [140]. They observed that the fluorescence intensity of CDs was decreased gradually with the addition of $\mathrm{Fe}^{2+}$ ions with increasing concentration. This technique is also used in determining the $\mathrm{Fe}^{2+}$ ions in syrup and iron tablets [140]. Wu et al. synthesized folic acid/3-aminopropyl trimethoxy silane based N, Si-doped CDs via one-step hydrothermal method and applied for sensing $\mathrm{Fe}^{3+}$ ions. They observed that $\mathrm{Fe}^{3+}$ ions could be detected using the as-synthesized CDs with a detection limit of $3.8 \mathrm{nM}$ [141]. Sun et al. fabricated red-emitting CDs via microwave irradiation of phenylenediamine and applied for detection of $\mathrm{Fe}^{3+}$ ions in aqueous solutions with a detection limit of $15 \mathrm{nM}$. They demonstrated that fluorescence of CDs get quenched significantly in presence of $\mathrm{Fe}^{3+}$ due to electron transfer mechanism [142]. Similar articles relating to the detection of $\mathrm{Fe}^{3+}$ were also published in the past few years $[105,143-145,155,156]$. Qian, et al. synthesized blue fluorescent $\mathrm{N}$-doped $\mathrm{CDs}$ from $\mathrm{CCl}_{4}$ and diamines for the detection of $\mathrm{Ag}^{+}$ion. Their results suggested that fluorescence intensity of the as-prepared CDs was inversely proportional to the $\mathrm{pH}$ values ranging from 5.0 and 13.5, indicating the possibility of using those $\mathrm{CDs}$ as a $\mathrm{pH}$ indicator. Besides, they also used the CDs for detection of $\mathrm{Ag}^{+}$, which increased the fluorescence intensity of CDs upon binding with the $\mathrm{N}$-atoms on their surface [146]. Binding of $\mathrm{Ag}^{+}$ions with the amino groups on the CDs surface leads to positive charges on CDs which decreased the collision among them and increased the fluorescence. Borse et al. also used N-doped CDs for the 'turn-off' dynamic fluorescence-based sensing of $\mathrm{Ag}^{+}$ions with detection within the concentration range of 1-1000 $\mu \mathrm{M}$ [111]. Ren et al. (2017) synthesized blue fluorescent $\mathrm{N}$-doped CDs from uric acid for the selective detection of $\mathrm{Ag}^{+}$and $\mathrm{Hg}^{2+}$ ions with detection limit of 1 and $4.8 \mathrm{nM}$ respectively. Besides, the quenching of fluorescence of $\mathrm{N}$-doped $\mathrm{CDs}$ could be recovered on the addition of EDTA [147]. Li et al. fabricated 1,2-diaminobenzene based N-doped CDs as a sensitive detection probe for $\mathrm{Ag}^{+}$with a detection limit of $0.5 \mathrm{nM}$ [148]. Wang et al. employed citric acid and amino acid derived carbon dots (CDs)-gold nanoparticles (AuNPs) hybrid for sensing $\mathrm{Ag}^{+}$ions in presence of glutathione. They demonstrated that on the addition of $\mathrm{Ag}^{+}$ions to a solution containing CDs-AuNPs and GSH, solution color changes from red to blue due to the aggregation of AuNP. This method could be used to detect $\mathrm{Ag}^{+}$ions with a detection limit of $50 \mathrm{nM}$ [149]. Recently, Qin et al. synthesized blue fluorescent CDs via pyrolysis of uric acids and $\mathrm{N}$, $\mathrm{S}$ co-doped CDs from citric acid and guanidine thiocyanate via hydrothermal method for the selective detection of $\mathrm{Ag}^{+}$ions $[150,151]$. Lin et al. used citric acid and poly(ethylenimine) based CDs in a zeolitic imidazolate framework and act as a selective detecting agent for $\mathrm{Cu}^{2+}$ ions with a detection limit of $80 \mathrm{pM}$. The intense blue emission of CD-nanocomposites was quenched following the addition of $\mathrm{Cu}^{2+}$ ions [12]. Zhang et al. fabricated citric acid based N doped CDs (NCDs) as the chemical sensing materials and applied for "turn off" detection of $\mathrm{Hg}^{2+}$ ions. That NCDs- $\mathrm{Hg}^{2+}$ system was further used for the selective and sensitive detection of L-cysteine via "turn on" mechanism with a detection limit of $79 \mathrm{nM}$ [6]. Fong et al. synthesized blue fluorescent CDs from sodium alginate for the detection of $\mathrm{Fe}^{3+}$ and ascorbic acid. They showed that $\mathrm{Fe}^{3+}$ ions decreased the fluorescence intensity (turn off) of the CDs, which was recovered by ascorbic acid addition (turn on) [91]. Sun et al. employed ascorbic acid, and glycol derived green fluorescent CDs 
for sensitive and selective detection of $\mathrm{Al}^{3+}$ ions with the detection limit of $0.39 \mu \mathrm{M}$ via fluorescence enhancement response. They demonstrated that the combination of $\mathrm{Al}^{3+}$ ions with the hydroxyl groups on CDs at nearly neutral $\mathrm{pH}$ resulted in the creation of much more surface state of the CDs, thereby increasing the fluorescence intensity. However, they also used the formed CDs- $\mathrm{Al}^{3+}$ ion system for selective and sensitive detection of $\mathrm{F}^{-}$anions with a detection limit of $0.14 \mu \mathrm{M}$ via fluorescence "on-off" mechanism due to the strong affinity of $\mathrm{F}^{-}$ions towards $\mathrm{Al}^{3+}$ ions [152].

Devi et al. used nitrogen-rich ligands functionalized CDs for selective detection of selenite $\left(\mathrm{SeO}_{3}{ }^{2-}\right)$ via fluorescence quenching mechanism (with the detection limit of $0.1 \mathrm{ppb}$ ) due to the formation of strong $\mathrm{Se}-\mathrm{N}$ bonds [153]. N and S co-doped CDs were prepared by Chen et al. form citric acid and 1,6-diaminohexane dihydrochloride and employed those for $\mathrm{Cr}^{6+}$ detection with the detection limit of $0.86 \mu \mathrm{M}$. They proposed that the fluorescence quenching of $\mathrm{CDs}$ by $\mathrm{Cr}^{6+}$ ions were due to the inner filter effect [154].

\section{Photocatalytic application}

CDs exhibit potential applications in the field of photocatalytic reactions due to their unique properties like better water solubility, very less toxicity, and high chemical stability compared with another common photocatalysts, such as $\mathrm{ZnO}, \mathrm{CdS}, \mathrm{TiO}_{2}$, etc. (Table 9). In addition, CDs can exhibit up-converted photoluminescence (UCPL) and photoinduced electron transfer properties which attract much interest in designing photocatalysts utilizing CDs [44]. Qu et al. fabricated S, N co-doped CDs/ $\mathrm{TiO}_{2}$ composites for the degradation of Rhodamine $\mathrm{B}$ $(\mathrm{RhB})$ as a visible light photocatalyst. They proposed that S, N: GQDs absorbed the visible light, and electronic excitation occurred from valence band (VB) to conduction band $(\mathrm{CB})$. The electrons were then injected from the $\mathrm{CB}$ of $\mathrm{CDs}$ to $\mathrm{CB}$ of $\mathrm{TiO}_{2}(\mathrm{CDs}$ acts as a sensitizer) and promoted the charge separation process. This charge separation process further generates superoxide and hydroxyl radicals which subsequently degraded the dye [157]. Yu et al. prepared CDs modified $\mathrm{TiO}_{2}$ (CDs/ P25) nanocomposites for efficient photocatalytic hydrogen evolution under both UV and visible light irradiation. When CDs/P25 was exposed to the UV light, CDs acted as electrons reservoir and improved the efficient separation between photo-induced electron-hole pairs. However, under visible light irradiation, CDs acted as a sensitizer and promote electron excitation in P25 [158]. Wang et al. used vitamin-C derived $\mathrm{CDs} / \mathrm{TiO} 2$ nanocomposites for hydrogen production from water. They demonstrated that the efficient electron transfer ability and up-conversion properties of CDs contributed to the enhanced photocatalytic behavior of $\mathrm{TiO} 2$ [159]. Martins et al. synthesized $\mathrm{N}$-doped $\mathrm{CDs} / \mathrm{TiO} 2$ composite with improved photocatalytic activity [160]. Cai et al. prepared S, N co-doped CDs/g- $\mathrm{C}_{3} \mathrm{~N}_{4}$ nanocomposites for the high catalytic performance in degrading $\mathrm{RhB}$ under visible light irradiation. They observed that $\mathrm{S}, \mathrm{N}$ doped GDs/g- $\mathrm{C}_{3} \mathrm{~N}_{4}$ nanocomposites exhibit better photocatalytic activity than pure $\mathrm{g}-\mathrm{C}_{3} \mathrm{~N}_{4}$ due to electron transfer from the $\mathrm{CB}$ of $\mathrm{g}-\mathrm{C}_{3} \mathrm{~N}_{4}$ to $\mathrm{CB}$ of $\mathrm{S}, \mathrm{N}$ doped GDs/g- $\mathrm{C}_{3} \mathrm{~N}_{4}$ (CDs act as an electron reservoir), results in the efficient separation of photogenerated electrons and holes [161]. Recently Zhang et al. fabricated CDs $/ \mathrm{La}_{2} \mathrm{Ti}_{2} \mathrm{O}_{7}$ nanocomposites for the degradation of RhB. The as-synthesized CDs absorbed visible light and converted it into UV light (due to its up-conversion properties) which was utilized by $\mathrm{La}_{2} \mathrm{Ti}_{2} \mathrm{O}_{7}$ for charge separation. Besides, the CDs were also capable of accepting electrons from $\mathrm{La}_{2} \mathrm{Ti}_{2} \mathrm{O}_{7}$, thereby promoting efficient separation of photogenerated electrons and holes [162]. Similar kind of photodegradation of RhB was also reported by several other researchers using CDs nanocomposites [163-166]. The zinc oxide reduced graphene oxide ( $\mathrm{ZnO}-\mathrm{RGO})$ nanocomposites were synthesized by Li et al. for the RhB photodegradation and $\mathrm{CO}_{2}$ photoreduction. They observed that $\mathrm{ZnO}-\mathrm{RGO}$ nanocomposites showed enhanced photocatalytic activity and the main reasons were: (1) RGO acted as electron acceptor, i.e. photoexcited electrons of $\mathrm{ZnO}$ transferred from its $\mathrm{CB}$ to the CB of RGO; (2) RGO absorbed a large number of dye molecules on their surface due to pi-stacking interaction [167]. They found that under the visible light irradiation $\mathrm{g}-\mathrm{C}_{3} \mathrm{~N}_{4}$ could be utilized for the photoreduction of $\mathrm{CO}_{2}$ to organic fuels. The urea derived g- $\mathrm{C}_{3} \mathrm{~N}_{4}$ showed better $\mathrm{CO}_{2}$ photoreduction due to their porous like structure and larger surface area than that of melamine derived $\mathrm{g}-\mathrm{C}_{3} \mathrm{~N}_{4}$ [168]. Sahu et al. fabricated Au-doped CDs from small acetic acid for the photoreduction of $\mathrm{CO}_{2}$ [169]. Cao et al. used Au or Ptcoated PEG-functionalized CDs as an active photocatalyst for the reduction of $\mathrm{CO}_{2}$. Surface functionalization with PEG increases the solubility of the catalysts allowing homogeneous reaction in the aqueous phase. The coated $\mathrm{Au}$ or Pt over the CD surface soaks up the photogenerated electrons, thereby disrupting the electron/hole recombination process [170].

Martindale et al. fabricated citric acid derived CDs via straightforward thermolysis route and combined it with molecular $\mathrm{Ni}$ catalyst [Ni-bis(diphosphine)] for solar hydrogen production [85]. Yan et al. used $\mathrm{N}$ doped CDs- $\mathrm{ZnNb}_{2} \mathrm{O}_{6} / g-\mathrm{C}_{3} \mathrm{~N}_{4}$ nanocomposite for photocatalytic hydrogen production. Under visible light irradiation, NGQDs absorbed light with wavelength $\geq 550 \mathrm{~nm}$ and converted them to shorter wavelength $<460 \mathrm{~nm}$ that was further used to excite $\mathrm{g}-\mathrm{C}_{3} \mathrm{~N}_{4}$ and to promote the 
Table 9 Role of in CDs in photocatalytic application

\begin{tabular}{|c|c|c|c|c|}
\hline S. No. & Nanomaterial & Source molecules & $\begin{array}{l}\text { Photocatalysis application/role } \\
\text { of support }\end{array}$ & Refs. No. \\
\hline 1. & $\mathrm{~S}, \mathrm{~N}$ doped $\mathrm{GDs} / \mathrm{TiO}_{2}$ & $\begin{array}{l}\text { Citric acid for c-dots and urea/thiourea } \\
\text { for N, S }\end{array}$ & Degradation of Rhodamine B & [157] \\
\hline 2. & $\mathrm{CDs} / \mathrm{Ag} / \mathrm{Ag}_{2} \mathrm{O}$ & Glucose & Rhodamine b & {$[174]$} \\
\hline 3. & $\mathrm{CDs} / \mathrm{g}-\mathrm{C}_{3} \mathrm{~N}_{4}$ & Citric acid, ethylenediamine & $\begin{array}{l}\text { Degradation of Rhodamine B and tetracy- } \\
\text { cline hydrochloride (TC-HCI) }\end{array}$ & {$[175]$} \\
\hline 4. & $\mathrm{~S}, \mathrm{~N}$ doped $\mathrm{GDs} / \mathrm{g}-\mathrm{C}_{3} \mathrm{~N}_{4}$ & Citric acid and thiourea & Rhodamine B (RhB) degradation & [161] \\
\hline 5. & $\mathrm{CDs} / \mathrm{Bi}_{2} \mathrm{O}_{3}$ & L-Ascorbic acid & degradation of Rhodamine $b$ & {$[165]$} \\
\hline 6. & $\begin{array}{l}\text { Ultrafine amorphous iron oxyhydroxide/ } \\
\text { ultrathin } g-C_{3} N_{4}\end{array}$ & Urea & $\begin{array}{l}\text { Degradation of Rhodamine } B \text {, methylene } \\
\text { blue, and methyl orange }\end{array}$ & [166] \\
\hline 7. & $\mathrm{CDs} / \mathrm{La}_{2} \mathrm{Ti}_{2} \mathrm{O}_{7}$ & Vitamin C and ethanol & Rhodamine B (RhB) & [173] \\
\hline 8. & Reduced graphene oxide/ZnO & Graphite oxide & $\mathrm{CO}_{2}$ photoreduction & [178] \\
\hline 9. & $\mathrm{~g}-\mathrm{C}_{3} \mathrm{~N}_{4}$ & Urea or melamine & Conversion of $\mathrm{CO}_{2}$ into methanol & [168] \\
\hline 10. & Au-doped CDs & Carbon-based & $\mathrm{CO}_{2}$ Photoreduction & [169] \\
\hline 11. & $\begin{array}{l}\text { PEG1500N-functionalized CDs with Au/ } \\
\text { Pt doping }\end{array}$ & Carbon-based & $\mathrm{H}_{2}$ generation, and $\mathrm{CO}_{2}$ photoreduction & {$[170]$} \\
\hline 12. & $\mathrm{CDs} / \mathrm{TiO}_{2}$ & Graphite & $\mathrm{H}_{2}$ generation & [170] \\
\hline 13. & $\mathrm{CDs} / \mathrm{TiO}_{2}$ & Vitamin C & $\mathrm{H}_{2}$ generation & [159] \\
\hline 14. & CDs & Citric acid & $\mathrm{H}_{2}$ generation & {$[85]$} \\
\hline 15. & $\begin{array}{l}\mathrm{N} \text { doped GDs- } \mathrm{ZnNb}{ }_{2} \mathrm{O}_{6} / \mathrm{g}-\mathrm{C}_{3} \mathrm{~N}_{4} \text { hetero- } \\
\text { structures }\end{array}$ & $\begin{array}{l}\text { Urea for } \mathrm{g}-\mathrm{C}_{3} \mathrm{~N}_{4} \text { and } \mathrm{C}_{6} \mathrm{H}_{5} \mathrm{O}_{7}\left(\mathrm{NH}_{4}\right)_{3}, \mathrm{NaOH} \\
\text { for } \mathrm{NGDs}\end{array}$ & $\mathrm{H}_{2}$ generation & [171] \\
\hline 16. & CDs/nitrogen-doped ZnO & Carbon black pigment & Methylene blue & [172] \\
\hline 17. & $\mathrm{~N}$ doped $\mathrm{CDs} / \mathrm{TiO}_{2}$ & Glycerol and TTDDA & Degradation of methylene blue & {$[160]$} \\
\hline 18. & $\mathrm{CDs} / \mathrm{Ag} / \mathrm{Ag}_{2} \mathrm{O}$ & Glucose & Degradation of methylene blue & {$[174]$} \\
\hline 19. & $\begin{array}{l}\text { Ultrafine amorphous iron oxyhydroxide/ } \\
\text { ultrathin } \mathrm{g}-\mathrm{C}_{3} \mathrm{~N}_{4} \text { nanosheets }\end{array}$ & Urea & Methylene blue, and methyl orange & {$[166]$} \\
\hline 20. & $\mathrm{Fe}(\mathrm{III}) / \mathrm{CDs}$ & $\begin{array}{l}\text { Oxidative coupling of Xylene by anhy- } \\
\text { drous FeCl3 }\end{array}$ & $\mathrm{H}_{2} \mathrm{O}_{2}$ reduction & [162] \\
\hline 21. & $\mathrm{CDs} /$ nitrogen-doped $\mathrm{ZnO}$ & Carbon black pigment & Degradation of malachite green & [172] \\
\hline 22. & $\mathrm{La} / \mathrm{Cu} / \mathrm{Zr} / \mathrm{CDs}$ & D-Fructose, $\mathrm{NaOH}$ & $\begin{array}{l}\text { Degradation of ampicillin antibiotic, } \\
\text { malachite green }\end{array}$ & {$[174]$} \\
\hline 23. & N doped CDs & Glucose and ammonia & Photodegradation of methyl orange & {$[175]$} \\
\hline 24. & $\begin{array}{l}\text { Ultrafine amorphous iron oxyhydroxide/ } \\
\text { ultrathin g-C } 3 \text { N4 nanosheets }\end{array}$ & Urea & Methyl orange & [166] \\
\hline 25. & $\mathrm{CDs} / \mathrm{Bi}_{2} \mathrm{WO}_{6}$ & Citric acid, ethylenediamine & $\begin{array}{l}\text { Degradation of methyl orange and } \\
\text { bisphenol A }\end{array}$ & {$[176]$} \\
\hline 26. & $\mathrm{CDs} / \mathrm{ZnFe}_{2} \mathrm{O}_{4}$ & $\begin{array}{l}\text { L-Ascorbic acid, glycol, and deionized } \\
\text { water }\end{array}$ & NO removal & [178] \\
\hline 27. & $\mathrm{~Pb}-\mathrm{CDs}-\mathrm{TiO}_{2}$ & Ascorbic acid and kollicoat & Degradation of RBX, CRB, and CNB dye & {$[177]$} \\
\hline 28. & $\mathrm{Ag}-\mathrm{CDs} / \mathrm{g}-\mathrm{C}_{3} \mathrm{~N}_{4}$ & Citric acid, ethylenediamine & Naproxcen & [179] \\
\hline 29. & $\mathrm{CDs} / \mathrm{g}-\mathrm{C}_{3} \mathrm{~N}_{4} / \mathrm{MoO}_{3}$ & Citric acid, urea and dicyandiamide & Degradation of tetracycline (TC) & [180] \\
\hline
\end{tabular}

generation of more electron-hole pairs. The electrons of $\mathrm{g}_{-} \mathrm{C}_{3} \mathrm{~N}_{4}$ in $\mathrm{CB}$ were further injected into the $\mathrm{CB}$ of the $\mathrm{ZnNb}_{2} \mathrm{O}_{6}$ and trapped by the Pt nanoparticles [171]. Ecofriendly $\mathrm{CDs} / \mathrm{N}$-doped $\mathrm{ZnO}$ nanocomposites were used by Muthulingam et al. for the degradation of methylene blue, fluorescein and malachite green dyes under the sunlight irradiation. It was noticed that $\mathrm{CDs}$ helped in electron/hole separation in $\mathrm{ZnO}$ via accepting the electrons from its $\mathrm{CB}$ and also exerted anti-photocorrosion property due to its coating over the $\mathrm{ZnO}$ surface [172]. Chen et al. synthesized $\mathrm{CDs} / \mathrm{Ag} / \mathrm{Ag}_{2} \mathrm{O}$ nanocomposites as an excellent photocatalyst for pollutant degradation via incorporating the photoinduced electron transfer and up-converted properties of CDs [163]. Yang et al. prepared ultrafine iron oxyhydroxide/g-C3N4 nanocomposites heterojunctions as an efficient photocatalyst in the presence of visible light. They observed that the ultrafine nanocomposites helped to increase the visible light 


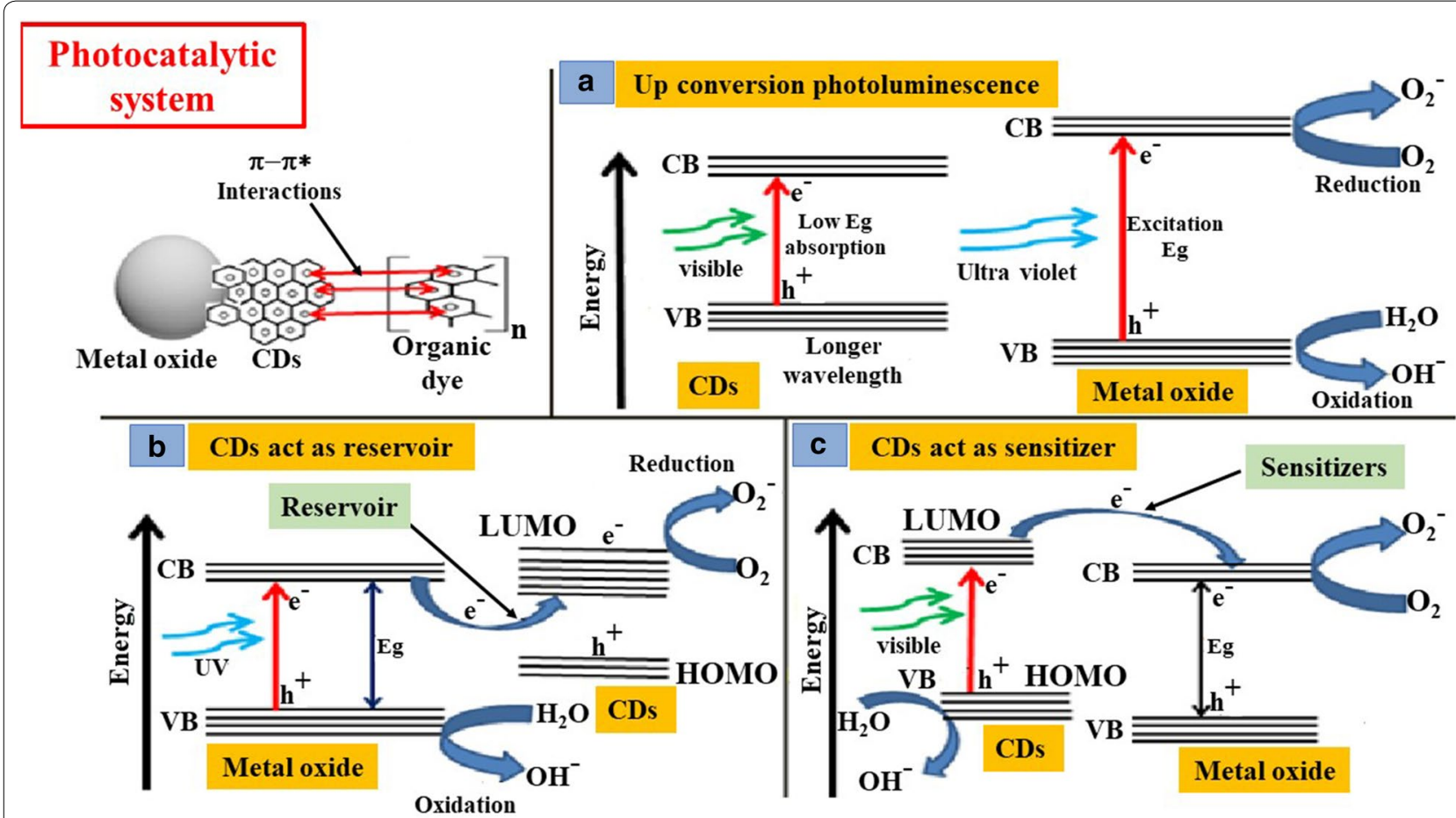

Fig. 5 Role of CDs in photocatalytic applications: CDs help in photocatalysis via different mechanisms, such as a up conversion photoluminescence of $C D s, \mathbf{b}$ action of $C D$ s as electron reservoir, $\mathbf{c}$ action of $C D$ s as sensitizer. Furthermore, the $\pi-\pi$ stacking between $C D$ s and organic dye also enhances its degradation upon light irradiation

absorbance, shortened the band gap of photogenerated carriers, and also helped in the formation of a large number of heterojunctions with $\mathrm{g}-\mathrm{C}_{3} \mathrm{~N}_{4}$ [166]. Bourlinos et al. synthesized $\mathrm{Fe}(\mathrm{III})$-functionalized $\mathrm{CDs}$ for catalytic decomposition of $\mathrm{H}_{2} \mathrm{O}_{2}$ and hydrogenation of olefin. It was observed that $\mathrm{Fe}(\mathrm{III})$-functionalized $\mathrm{CDs}$ were more useful for the hydrogenation of electron withdrawing or donating olefin substrates than heterogeneous or homogeneous Fe(III)-based photocatalysts [173].

Mao et al. synthesized two types of g- $\mathrm{C}_{3} \mathrm{~N}_{4}$ from melamine and urea via pyrolysis method.

Several other researchers also used CDs nanocomposites for the photocatalytic degradation of ampicillin antibiotic [174], organic/industrial dyes [175-177], NO [178], naproxcen [179], and tetracycline [180]. The overall mechanisms of action behind the photocatalytic applications CDs have been depicted in Fig. 5.

\section{Photo-dynamic therapy (PDT) and Photo-thermal (PTT) therapy}

Photo-dynamic therapy (PDT) and Photo-thermal therapy (PTT) are applied for the treatment of cancer using laser light (most often by near IR radiations). PTT refers to the use of NIR which is absorbed by a photoabsorber to generate local heat, and destroy diseased tissue. PTT offers several advantages over the conventional chemotherapy, radiotherapy, and surgery; therefore attracting much interests of the researchers in the field of cancer treatment. However, the effectiveness of nanomaterials as photothermal agent (gold nanostructures, graphene and graphene oxide) in PTT is still under consideration due to the difficulties in their synthesis, and high production cost. Unlike the PTT, PDT requires $\mathrm{O}_{2}$ to produce ROS and destroy targeted cells. In PDT, a photosensitizer is irradiated with laser light that produces ROS which ultimately destroys the cancer cells/tissue. Upon excitation with a suitable wavelength, photosensitizer gets excited from its ground singlet state to higher energy singlet state and suffers intersystem crossing to form long lived triplet state. The triplet state reacts with oxygen molecule, resulting in ROS that can effectively destroy cancer cells [181]. Recently CDs are intensively used by researchers in PTT and PDT due to its smooth and low-cost synthesis, facile surface functionalization and superior caring capacity, excellent biocompatibility and ability to convert absorbed light into heat due to a large number of pi electrons (Table 10). Both PDT and PTT are involving the use of light having less energy and hence is less injurious to healthy cells/tissue [113]. Ge et al. fabricated red-fluorescent CDs from polythiophene phenylpropionic acid for 
Table 10 Role of CDs in photo-dynamic therapy (PDT) and photo-thermal (PTT) therapy

\begin{tabular}{|c|c|c|c|c|}
\hline S. No. & Source molecule & Ligand attached & Targeted cell type & Refs. No. \\
\hline 1. & Polythiophene phenylpropionic acid & - & Hela cells & [182] \\
\hline 2. & Diaminohexane and carboxylic group of Ce6 & Ce6-HA (hyaluronate) & B16F10 melanoma & [185] \\
\hline 3. & Acrylic acid, 1, 2-ethylenediamine (EDA) and $\mathrm{Mg}(\mathrm{OH})_{2}$ & $\mathrm{Mg} / \mathrm{N}$ & HepG2 & [10] \\
\hline 4. & Hydrophobic cyanine dye and poly(ethylene glycol) & - & HepG2, CT26 & [183] \\
\hline 5. & Citric acid and urea & - & HeLa & [184] \\
\hline 6. & Dopamine & - & Hela cells & [181] \\
\hline 7. & Urea & Carbon nitride $\left(\mathrm{C}_{3} \mathrm{~N}_{4}\right)$ & $4 \mathrm{~T} 1$ & [186] \\
\hline 8. & Citric acid and 5,10,15,20-tetrakis(4-aminophenyl)porphyrin & Cetuximab (C225) & HCC827 and MDA-MB-231 cells & [187] \\
\hline 9. & m-Phenylenediamine and L-cysteine & Protoporphyrin IX (PpIX) & HeLa & [188] \\
\hline 10. & $\mathrm{EDTA} \cdot 2 \mathrm{Na}$ and $\mathrm{CuCl}_{2}$ & - & Murine melanoma (B16) cells & [189] \\
\hline
\end{tabular}

photoacoustic/FL (NIR) imaging and in vitro as well as in vivo photo-thermal therapy. They demonstrated that the as-synthesized CDs showed extensive cytotoxicity towards HeLa cells upon NIR laser irradiation. The CDs were also found to show in vivo PTT efficacy in HeLa tumor bearing mice without any sign of systemic toxicity [182]. Zheng et al. fabricated CDs from hydrophobic cyanine dye and poly(ethylene glycol) for NIR imaging and in vitro as well as in vivo photothermal therapy. The as-prepared CDs exhibit superior photothermal effect in HepG2 and CT26 cells upon NIR laser irradiation. The CDs were also effective in inhibiting tumor growth in CT26 xenograft Babl-c mice upon NIR laser irradiation [183]. Li et al. synthesized supra-CDs from citric acid, and urea via electrostatic interactions and hydrogen bonding. The as-prepared supra-CDs showed strong visible-NIR absorption with high photothermal conversion efficiency [184]. Beack et al. synthesized CDs-Ce6-HA, hyaluronic acid modified CDs conjugated with chlorineCe6 (Ce6, a photosensitizer) for targeted therapy of melanoma skin cancer. They observed that CDs conjugation to $\mathrm{Ce} 6$ increased the photodynamic reaction of $\mathrm{Ce} 6$, and produce more singlet oxygen than free Ce6. Transdermal administration of CDs-Ce6-HA resulted in suppression of B16F10 melanoma cells in tumor mice upon laser irradiation [185]. Yang et al. fabricated $\mathrm{Mg} / \mathrm{N}$ doped $\mathrm{CDs}$ and used them as a carrier of Ce6. This CDs/Ce6 composite showed high fluorescence resonance energy transfer (FRET) efficiency and subsequently enhanced the PDT effect. They also demonstrated that CDs conjugation to Ce6 increased the production of singlet oxygen almost two times than the free Ce6, and a significantly enhanced PDT effect was observed in HepG2 cancer cells compared with free Ce6 [10]. Zheng et al. synthesized carbon nitride $\left(\mathrm{C}_{3} \mathrm{~N}_{4}\right)$ doped $\mathrm{CDs}$ and functionalized it with a targeting agent and a photosensitizer to increase the targeted PDT efficiency in solid tumor under hypoxic condition. They demonstrated that the nanocomposite produces oxygen inside the hypoxic tumor region via splitting of water upon light exposure, thereby producing ROS and showed enhanced PDT efficiency under both in vitro and in vivo conditions [186].

$\mathrm{Wu}$ et al. synthesized porphyrin implanted CDs from citric acid and 5,10,15,20-tetrakis(4-aminophenyl)porphyrin via selective pyrolysis treatment. They demonstrated that the as-prepared CDs could act as an active agent for photoacoustic molecular imaging under NIR irradiation. Furthermore, cetuximab-conjugated CDs exhibit superior photodynamic effect in HCC827 and MDA-MB-231 cancer cells as well as MDA-MB-231 tumor bearing mice [187].

Recently Hua et al. synthesized CDs from L-cysteine and $\mathrm{m}$-phenylenediamine. The as-prepared CDs showed nucleus targeting property, thereby could be used as a nucleus staining agent. They further conjugated the CDs with protoporphyrin IX (a photosensitizer), which showed enhanced PDT efficacy in vivo without affecting healthy cells [188]. Guo et al. synthesized $\mathrm{Cu}, \mathrm{N}$ codoped CDs via one-step hydrothermal treatment using EDTA.2Na and $\mathrm{CuCl}_{2}$. They demonstrated that the assynthesized $\mathrm{Cu}, \mathrm{N}$ co-doped $\mathrm{CDs}$ significantly inhibited cancer (B16 melanoma) cell growth via photodynamic and photo-thermal therapy. In addition it could also act as an active agent in FL cell-imaging and IR thermal imaging to visualize in vivo and in vitro treatment process [189]. The Role of CDs in photo thermal (PTT) and photo dynamic (PDT) therapy has been depicted in Fig. 6.

\section{Conclusion and future perspective}

The first report of CDs synthesis was registered in 2004 as the new fellow of carbon family and attained tremendous attention in the area of chemistry and biology due to their economical and facile synthesis methods, easy surface modification, excellent photoluminescence, and superior water solubility. 


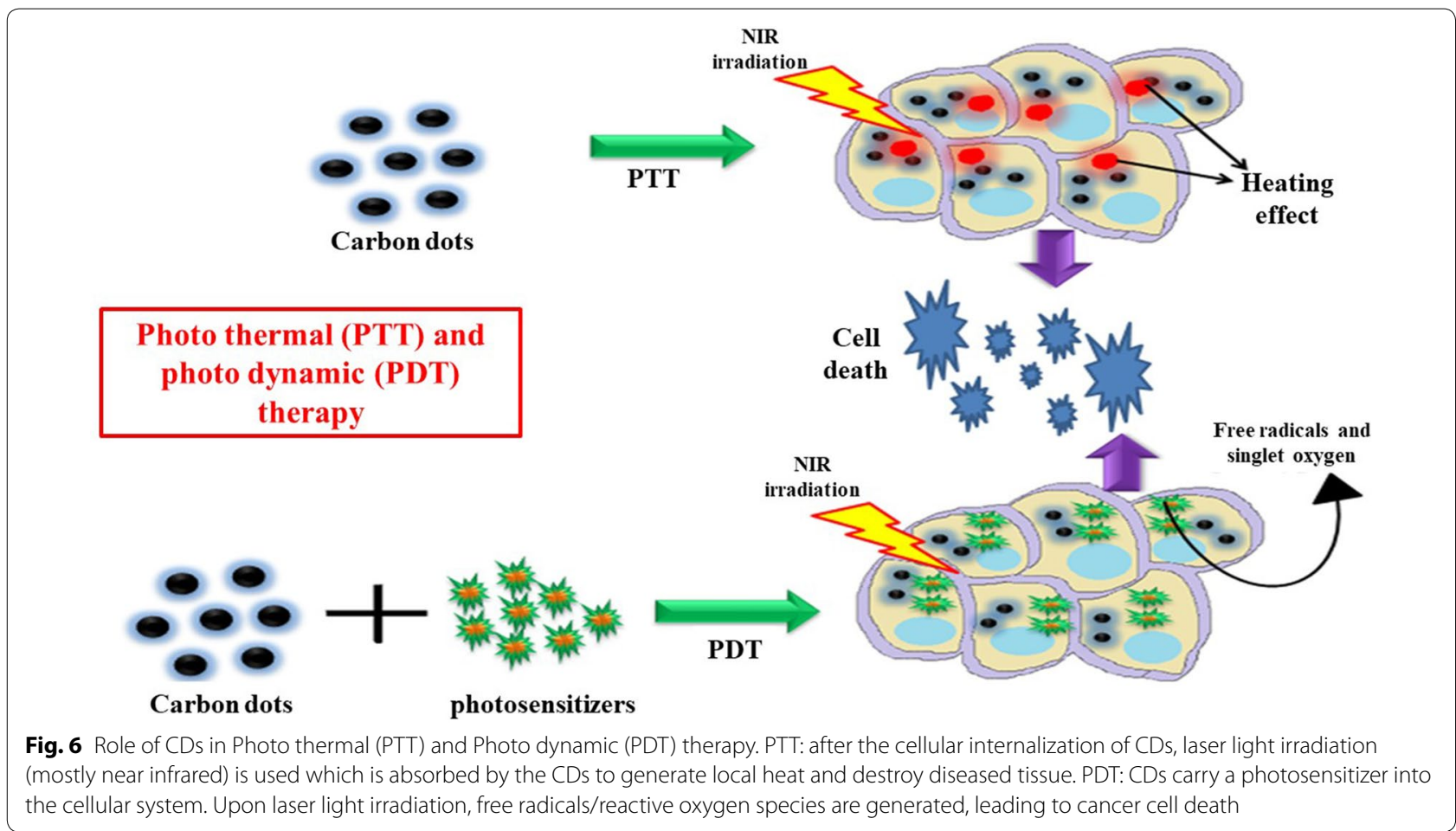

CDs can be extensively applied in photocatalytic reactions, in vitro, and in vivo bioimaging, drug-gene delivery system, chemical and biological sensing as well as in photodynamic and photothermal therapies. This review summarized the progress of research on CDs regarding its synthesis from small organic molecules and applications in biological as well as chemical field till date. Although significant development has been done in those areas over the past decade, still some difficulties need to be addressed related to the synthesis and applications of CDs as follows:

- The synthesis of CDs with uniform size distribution is somehow tricky. The size distribution plays a crucial role to decide its toxicity and fluorescence properties which may obstruct further biological applications, particularly in vivo. CDs reproducibility is also a big issue for clinical applications. Besides, different synthesis methods of CDs result in different QY, size, fluorescence color, etc. which obstruct CDs commercialization.

- Despite enormous research on CDs synthesis and its modifications, the real mechanism of CDs formation is not understood fully till date. Furthermore, simple and controllable surface modifications are still crucial problems, which may help for designing CDs with excellent photoluminescence property and other applications with high efficiency.
- Although CDs based chemical and, bio-sensing technology is well applicable in real life samples, but studies on several other toxic metal ions, like $\mathrm{Cd}^{2+}, \mathrm{Mn}^{2+}, \mathrm{As}^{3+}, \mathrm{Po}^{3+}$, etc. are still missing. Therefore, further research with those metal ions should be done to understand the full potential of CDs as a sensing agent.

- More efforts are needed to apply the CDs in the field of in vivo imaging, drug and gene delivery systems as well as cancer therapies to broaden the area of its applications. Furthermore, dual drug-gene delivery systems are not fully explored to date.

- Finally, the use of CDs in the area of energy storage is needed to be explored. Therefore, researchers should concentrate on those above-said issues and CDs will gain significant interest in the future undoubtedly after proper addressing such problems.

\section{Acknowledgements}

Authors would like to acknowledge the Scientific Writing Cell, Shoolini University for the support provided towards language editing of the manuscript.

\section{Authors' contributions}

AS, and JD contributed equally to the research and review of literature, organization and writing of this review article. Both authors read and approved the final manuscript.

Funding

This research study did not receive any specific grant from funding agencies. 


\section{Availability of data and materials}

Not applicable.

\section{Ethics approval and consent to participate}

Not applicable.

\section{Consent for publication}

Not applicable.

\section{Competing interests}

The authors declare that they have no competing interests.

Received: 12 June 2019 Accepted: 19 August 2019

Published online: 26 August 2019

\section{References}

1. Wang Y, Hu A. Carbon quantum dots: synthesis, properties and applications. J Mater Chem C. 2014;2:6921-39.

2. Dong Y, Wang R, Li H, Shao J, Chi Y, Lin X, Chen G. Polyamine-functionalized carbon quantum dots for chemical sensing. Anal Chem. 2012;84(14):6220-4

3. Tao H, Yang K, Ma Z, Wan J, Zhang Y, Kang Z, Liu Z. In vivo NIR fluorescence imaging, biodistribution, and toxicology of photoluminescent carbon dots produced from carbon nanotubes and graphite. Small. 2012;8(2):281-90.

4. Gao X, Cui Y, Levenson RM, Chung LW, Nie S. In vivo cancer targeting and imaging with semiconductor quantum dots. Nat Biotechnol. 2004;22(8):969-76.

5. Peng $H$, Zhang L, Kjällman THM, Soeller C. DNA hybridization detection with blue luminescent quantum dots and dye-labeled single-stranded DNA. Communication. 2007;129(11):3048-9.

6. Zhang Y, Cui P, Zhang F, Feng X, Wang Y, Yang Y, Liu X. Fluorescent probes for "off-on" highly sensitive detection of $\mathrm{Hg}^{2+}$ and L-cysteine based on nitrogen-doped carbon dots. Talanta. 2016;152:288-300.

7. Sharma V, Tiwari P, Mobin SM. Sustainable carbon-dots: recent advances in green carbon dots for sensing and bioimaging. J Mater Chem B. 2017:5(45):8904-24

8. Chen F, Gao W, Qiu X, Zhang H, Liu L, Liao P, Fu W, Luo Y. Graphene quantum dots in biomedical applications: recent advances and future challenges. Front Lab Med. 2017;1(4):192-9.

9. Liu C, Zhang P, Zhai X, Tian F, Li W, Yang J, Liu Y, Wang H, Wang W, Liu W. Nanocarrier for gene delivery and bioimaging based on carbon dots with PEI passivation enhanced fluorescence. Biomaterials. 2012;33(13):3604-13.

10. Yang K, Li F, Che W, Hu X, Liu C, Tian F. Increment of the FRET efficiency between carbon dots and photosensitizers for enhanced photodynamic therapy. RSC Adv. 2016;6(103):101447-51.

11. Feng $T, A i X, A n G$, Yang P, Zhao Y. Charge-convertible carbon dots for imaging-guided drug delivery with enhanced in vivo cancer therapeutic efficiency. ACS Nano. 2016;10(4):4410-20.

12. Lin X, Gao G, Zheng L, Chi Y, Chen G. Encapsulation of strongly fluorescent carbon quantum dots in metal-organic frameworks for enhancing chemical sensing. Anal Chem. 2014;86(2):1223-8.

13. Guo $Y$, Wang $Z$, Shao $H$, Jiang $X$. Hydrothermal synthesis of highly fluorescent carbon nanoparticles from sodium citrate and their use for the detection of mercury ions. Carbon. 2013;52:583-9.

14. Lin H, Ding L, Zhang B, Huang J. Detection of nitrite based on fluorescent carbon dots by the hydrothermal method with folic acid. R Soc Open Sci. 2018:5(5):2054-5703.

15. Shan X, Chai L, Ma J, Qian Z, Chen J, Feng H. B-doped carbon quantum dots as a sensitive fluorescence probe for hydrogen peroxide and glucose detection. Analyst. 2014;139(10):2322-5

16. Guo X, Zhu Y, Zhou L, Zhang L, You Y, Zhang H, Hao J. A simple and green approach to prepare carbon dots with $\mathrm{pH}$-dependent fluorescence for patterning and bioimaging. RSC Adv. 2018;8(66):38091-9.

17. Wu X, Tian F, Wang W, Chen J, Wu M, Zhao JX. Fabrication of highly fluorescent graphene quantum dots using L-glutamic acid for in vitro/ in vivo imaging and sensing. J Mater Chem C. 2013;1(31):4676-84.
18. Pirsaheb M, Asadi A, Sillanpää M, Farhadian N. Application of carbon quantum dots to increase the activity of conventional photocatalysts: a systematic review. J Mol Liq. 2018:271:857-71.

19. SahuS LiuY, WangP BunkerCE, FernandoKAS LewisWK, GuliantsEA YangF, WangJ SunYP. Visible-light photoconversion of carbon dioxide into organic acids in an aqueous solution of carbon dots. Langmuir. 2014;30(28):8631-6.

20. Yang P, Zhao J, Wang J, Cui H, Li L, Zhu Z. Pure carbon nanodots for excellent photocatalytic hydrogen generation. RSC Adv. 2015;5(27):21332-5.

21. Xu X, Ray R, Gu Y, Ploehn HJ, Gearheart L, Raker K, Scrivens WA, Walter A. Electrophoretic analysis and purification of fluorescent singlewalled carbon nanotube. J Am Chem Soc. 2004;126(40):12736-7.

22. Sun YP, Zhou B, Lin Y, Wang W, Fernando KS, Pathak P, Meziani MJ, Harruff BA, Wang $X$, Wang $H$. Quantum-sized carbon dots for bright and colorful photoluminescence. J Am Chem Soc. 2006;128(24):7756-7.

23. Sagbas S, Sahiner N. Carbon dots: preparation, properties, and application. In: Nanocarbon and its Composites, Chap 22, Elsevier Ltd, Amsterdam, Netherlands, 2019. https://doi.org/10.1016/B978-008-102509-3.00022-5.

24. Wang Cl, Wu WC, Periasamy AP, Chang HT. Electrochemical synthesis of photoluminescent carbon nanodots from glycine for highly sensitive detection of hemoglobin. Green Chem. 2014;16(5):2509-14.

25. Lim SY, Shen W, Gao Z. Carbon quantum dots and their applications. Chem Soc Rev. 2015;44(1):362-81.

26. Zhou J, Booker C, Li R, Zhou X, Sun X, Ding Z. An electrochemical avenue to blue luminescent nanocrystals from multiwalled carbon nanotubes (MWCNTs). J Am Chem Soc. 2007;129(4):744-5.

27. Zeng Q, Shao D, He X, Ren Z, Ji W, Shan C, Qu S, Li J, Chen L, Li Q. Carbon dots as a trackable drug delivery carrier for localized cancer therapy in vivo. J Mater Chem B. 2016:4(30):5119-26.

28. Rai S, Singh BK, Bhartiya P, Singh A, Kumar H, Dutta PK, Mehrotra GK Lignin derived reduced fluorescence carbon dots with theranostic approaches: nano-drug-carrier and bioimaging. J Luminescence. 2017; 190:492-503

29. Qian Z, Shan X, Chai L, Ma J, Chen J, Feng H. Si-doped carbon quantum dots: a facile and general preparation strategy, bioimaging application, and multifunctional sensor. ACS Appl Mater Interfaces. 2014;6(9):6797-805.

30. Li H, He X, Liu Y, Huang H, Lian S, Lee S, Kang Z. One-step ultrasonic synthesis of water-soluble carbon nanoparticles with excellent photoluminescent properties. Carbon. 2011:49(2):605-9.

31. Bourlinos AB, Trivizas G, Karakassides MA, Baikousi M, Kouloumpis A, Gournis D, Bakandritsos A, Hola K, Kozak O, Zboril R, Papagiannouli I, Aloukos P, Couris S. Green and simple route toward boron doped carbon dots with significantly enhanced non-linear optical properties. Carbon. 2015;83:173-9.

32. Miao X, Qu D, Yang D, Nie B, Zhao Y, Fan H, Sun Z. Synthesis of carbon dots with multiple color emission by controlled graphitization and surface functionalization. Adv Mater. 2017;30:1704740.

33. Dang $H$, Huang LK, Zhang Y, Wang CF, Chen S. Large-scale ultrasonic fabrication of white fluorescent carbon dots. Ind Eng Chem Res. 2016:55(18):5335-41.

34. Wang S, Chen ZG, Cole I, Li Q. Structural evolution of graphene quantum dots during thermal decomposition of citric acid and the corresponding photoluminescence. Carbon. 2015;82:304-13.

35. Wang Y, Zhu Y, Yu S, Jiang C. Fluorescent carbon dots: rational synthesis, tunable optical properties, and analytical applications. RSC Adv. 2017;7(65):40973-89.

36. Zhang Y, Ma D, Zhuang Y, Zhang X, Chen W, Hong L, Yan Q, Yu K, Huang S. One-pot synthesis of $\mathrm{N}$-doped carbon dots with tunable luminescence properties. J Mater Chem. 2012;22(33):16714-8.

37. Qu K, Wang J, Ren J, Qu X. Carbon dots prepared by hydrothermal treatment of dopamine as an effective fluorescent sensing platform for the label-free detection of iron (III) ions and dopamine. Chem A Eur J. 2013;19(22):7243-9.

38. Wang X, Shen X, Li B, Jiang G, Zhou X, Jiang H. One-step facile synthesis of novel beta amino alcohol functionalized carbon dots for the fabrication of selective. RSC Adv. 2016:6(22):18326-32.

39. Zhu S, Meng Q, Wang L, Zhang J, Song Y, Jin H, Zhang K, Sun H, Wang $\mathrm{H}$, Yang B. Highly photoluminescent carbon dots for multicolor 
patterning, sensors, and bioimaging. Angew Chem Int Ed Engl. 2013;125(14):4045-9.

40. Ray S, Saha A, Jana NR, Sarkar R. Fluorescent carbon nanoparticles: synthesis, characterization, and bioimaging application. J Phys Chem C. 2009;113(43):18546-51.

41. Yu H, Li X, Zeng X, Lu Y. Preparation of carbon dots by non-focusing pulsed laser irradiation in toluene. Chem Commun. 2015;52(4):819-22.

42. Shi W, Wang Q, Long Y, Cheng Z, Chen S, Zheng H, Huang Y. Carbon nanodots as peroxidase mimetics and their applications to glucose detection. Chem Commun. 2011:47(23):6695-7.

43. Hu S, Guo Y, Tian R. Synthesis and size control of carbon quantum dots by tailoring laser parameters. In: International conference on electronics and optoelectronics; 2011. INSPEC Accession Number: 12228167.

44. Wang R, LuK Q, Tang ZR, Xu YJ. Recent progress in carbon quantum dots: synthesis, properties, and applications in photocatalysis. J Mater Chem A. 2017:5(8):3717-34.

45. Wang Y, Hu A. Carbon quantum dots: synthesis, properties and applications. J Mater Chem C. 2014;2(34):6921-39.

46. Peng H, Sejdic JT. Simple aqueous solution route to luminescent carbogenic dots from carbohydrates. Chem Mater. 2009;21(23):5563-5.

47. Deng J, Lu Q, Mi N, Li H, Liu M, Xu M, Tan L, Xie Q, Zhang Y, Yao S. Electrochemical synthesis of carbon nanodots directly from alcohols. Chem A Eur J. 2014;20(17):4993-9.

48. Hou Y, Lu Q, Deng J, Li H, Zhang Y. One-pot electrochemical synthesis of functionalized fluorescent carbon dots and their selective sensing for mercury ion. Anal Chim Acta. 2015;866:69-74.

49. Liu M, Xu Y, Niu F, Gooding JJ, Liu J. Carbon quantum dots directly generated from electrochemical oxidation of graphite electrodes in alkaline alcohols and the applications for specific ferric ion detection and cell imaging. Analyst. 2016;141(9):2657-64.

50. Nguyen V, Yan L, Si J, Hou X. Femtosecond laser-induced size reduction of carbon nanodots in solution: effect of laser fluence, spot size, and irradiation time. J Appl Phys. 2015;117(8):084304.

51. Wang F, Wang S, Sun Z, Zhu H. Study on the ultrasonic single-step synthesis and optical properties of nitrogen-doped carbon fluorescent quantum dots. Fullerenes Nanotubes Carbon Nanostruct. 2015;23(9):769-76.

52. Yang ZC, Wang M, Yong AM, Wong SY, Zhang XH, Tan H, Chang AY, L $X$, Wang J. Intrinsically fluorescent carbon dots with tunable emission derived from hydrothermal treatment of glucose in the presence of monopotassium phosphate. Chem Commun. 2011;47(42):11615-7.

53. Zhang B, Liu C, Liu Y. A novel one-step approach to synthesize fluorescent carbon nanoparticles. Eur J Inorg Chem. 2010;2010(28):4411-4.

54. Li Z, Yu H, Bian T, Zhao Y, Zhou C, Shang L, Liu Y, Wu L, Tung C, Zhang T. Highly luminescent nitrogen-doped carbon quantum dots as effective fluorescent probes for mercuric and iodide ions. J Mater Chem C. 2015;3(9):1922-8

55. Zeng Y, Ma D, Wang W, Chen J, Zhou L, Zheng Y, Yu K, Huang S. N, S co-doped carbon dots with orange luminescence synthesized through polymerization and carbonization reaction of amino acids. Appl Surf Sci. 2015;342:136-43.

56. LiJ Y, Liu Y, Shu QW, Liang JM, Zhang F, Chen XP, Deng XY, Swihart MT, Tan KJ. One-pot hydrothermal synthesis of carbon dots with efficient up- and down-converted photoluminescence for the sensitive detection of morin in a dual-readout assay. Langmuir. 2017;33(4):1043-50.

57. Yang Z, Li X, Wang J. Intrinsically fluorescent nitrogen-containing carbon nanoparticles synthesized by a hydrothermal process. Carbon. 2011:49(15):5207-521.

58. Zhu S, Meng Q, Wang L, Zhang J, Song $Y$, Jin $H$, Zhang K, Sun $H$, Wang $\mathrm{H}$, Yang B. Highly photoluminescent carbon dots for multicolor patterning, sensors, and bioimaging. Angew Chem Int Ed Engl. 2013;125:4045-9.

59. Hu L, Sun Y, Li S, Wang X, Hu K, Wang L, Liang X, Wu Y. Multifunctional carbon dots with the high quantum yield for imaging and gene delivery. Carbon. 2014;67:508-13.

60. Wang W, Lu Y, Huang H, Feng J, Chen J, Wang A. Facile synthesis ofwater-soluble and biocompatible fluorescent nitrogen-doped carbon dots for cell imaging. Analyst. 2014;139(7):1692-6.

61. Dai H, Shi Y, Wang Y, Sun Y, Hu J, Ni P, Li Z. A carbon dot based biosensor for melamine detection by fluorescence resonance energy transfer. Sens Actuators B Chem. 2014:202:201-8.
62. Kuruvilla SJ, Li S, Sansalone L, Fortes B, Zheng I, Blackwelder P, Pumilia C, Micic M, Orbulescu J, Leblanc RM. Dihydrolipoic acid conjugated carbon dots accelerate human insulin fibrillation. J Parkinsons Dis Alzheimer Dis. 2015;2:1-7.

63. Jiang $Y$, Han Q, Jin C, Wang B. A fluorescence turn-off chemosensor based on $\mathrm{N}$ doped carbon quantum dots for detection of $\mathrm{Fe} 3+$ in aqueous solution. Mater Lett. 2015:141:366-8.

64. Cai QY, Li J, Ge J, Zhang L, Hu YL, Li ZH, Qu LB. A rapid fluorescence "switch-on" assay for glutathione detection by using carbon dots-MnO2 nanocomposites. Biosens Bioelectron. 2015;72:31-6.

65. Zhuo Y, Miao H, Zhong D, Zhu S, Yang X. One-step synthesis of high quantum-yield and excitation-independent emission carbon dots for cell imaging. Mater Lett. 2015;139:197-200.

66. Loo AH, Sofer Z, Bouša D, Ulbrich P, Bonanni A. Carboxylic carbon quantum dots as a fluorescent sensing platform for DNA detection Pumera MACS. Appl Mater Interfaces. 2016;8(3):1951-7.

67. Campos BB, Oliva MM, Cáceres RC, Castellón ER, Jiménez JJ, da Silva JCGE, Algarra M. Carbon dots on based folic acid coated with PAMAM dendrimer as platform for Pt(IV) detection. J Colloid Interface Sci. 2016:465:165-73.

68. Tang L, Ji R, Cao X, Lin J, Jiang H, Li X, Teng KS, Luk CM, Zeng S, Hao J, Lau SP. Deep ultraviolet photoluminescence of water-soluble selfpassivated graphene quantum dots. ACS Nano. 2012;6(6):5102-10.

69. Lu S, Wu D, Li G, Lv Z, Chen L, Chen Z, Chen G, Xia L, You J, Wu Y. Carbon dots-based ratiometricnanosensor for highly sensitive and selective detection of mercury(II) ions and glutathione. RSC Adv. 2016;6(105):103169-77.

70. Zou C, Foda MF, Tan X, Shao K, Wu L, Lu Z, Bahlol HS, Han H. Carbondot and quantum-dot-coated dual-emission Core-satellite silica nanoparticles for ratiometric intracellular $\mathrm{Cu}(2+)$ imaging. Anal Chem. 2016:88(14):7395-403.

71. Zhai X, Zhang P, Liu C, Bai T, Li W, Da L, Liu W. Highly luminescent carbon nanodots by microwave-assisted pyrolysis. Chem Commun. 2012;48(64):7955-7.

72. Liu Y, Xiao N, Gong N, Wang H, Shi X, Gu W, Ye L. Microwave-assisted polyol synthesis of gadolinium-doped green luminescent carbon dots as a bimodal nanoprobe. Carbon. 2014;30(36):10933-9.

73. Zhu H, Wang X, Li Y, Wang Z, Yang F, Yang X. Microwave synthesis of fluorescent carbon nanoparticles with electrochemiluminescence properties. Chem Commun. 2009. https://doi.org/10.1039/B907612C.

74. Wang Q, Zhang C, Shen G, Liu H, Fu H, Cui D. Fluorescent carbon dots as an efficient siRNA nanocarrier for its interference therapy in gastric cancer cells. J Nanobiotechnol. 2014;12:58.

75. Kiran S, Misra RDK. Mechanism of intracellular detection of glucose through nonenzymatic and boronic acid functionalized carbon dots. J Biomed Mater Res Part A. 2015;103(9):2888-97.

76. Cao X, Wang J, Deng W, Chen J, Wang Y, Zhou J, Du P, Xu W, Wang Q, Wang Q, Yu Q, Spector M, Yu J, Xu X. Photoluminescent cationic carbon dots as efficient non-viral delivery of plasmid SOX9 and chondrogenesis of fibroblasts. Scientific Rep. 2018;8:7057.

77. Wang X, Qu K, Xu B, Ren J, Qu X. Microwave-assisted the one-step green synthesis of cell-permeable multicolor photoluminescent carbon dots without surface passivation reagents. J Mater Chem. 2011;21(8):2445-50.

78. Wang Q, Zhang C, Shen G, Liu H, Fu H, Cui D. Fluorescent carbon dots as an efficient siRNA nanocarrier for its interference therapy in gastric cancer cells. J Nanobiotechnol. 2014:12:12-58.

79. Liu H, Wang Q, Shen G, Zhang C, Li C, Ji W, Wang C, Cui D. A multifunctional ribonuclease A-conjugated carbon dot nanosystem cluster for synchronous cancer imaging and therapy. Nanoscale Res Lett. 2014;9(15):397.

80. Lei CH, Zhao XE, Jiao SL, He L, Li Y, Zhu SY, You JMA. turn-on fluorescent sensor for detection of melamine based on the anti-quenching ability of Hg2+ to carbon nanodots. Anal Methods. 2016;8(22):4438-44.

81. Wu Y, Wu H, Kuan C, Lin C, Wang L, Chang C, Wang T. Multi-functionalized carbon dots as theranosticnanoagent for gene delivery in lung cancer therapy. Sci. Rep. 2016;6:1-12.

82. Wang F, Xie Z, Zhang H, Liu CY, Zhang YG. Highly luminescent organosilane-functionalized carbon dots. Adv Funct Mater. 2011;21 (6):1027-31. 
83. Wan JY, Yang Z, Liu ZG, Wang HX. lonic liquid-assisted thermal decomposition synthesis of carbon dots and graphene-like carbon sheets for optoelectronic application. RSC Adv. 2016;6(66):61292-300.

84. Zheng M, Xie Z, Qu D, Li D, Du P, Jing X, Sun Z. On-Off-On fluorescent carbon dot nanosensor for recognition of chromium( $\mathrm{VI})$ and ascorbic acid based on the inner filter effect. ACS Appl Mater Interfaces. 2013:5(24):13242-7.

85. Martindale BC, Hutton GA, Caputo CA, Reisner E. Solar hydrogen production using carbon quantum dots and a molecular nickel catalyst. J Am Chem Soc. 2015;137(18):6018-25.

86. Hou J, Wang W, Zhou T, Wang B, Li H, Ding L. Synthesis and formation mechanistic investigation of nitrogen-doped carbon dots with high quantum yield and yellowish-green fluorescence. NANO. 2016;8(21):11185-93.

87. Wei $X, X u Y, L i Y, Y i n X, H e X$. Ultrafast synthesis of nitrogen-doped carbon dots via neutralization heat for bioimaging and sensing. RSC Adv. 2014;4(84):44504-8

88. Wang J, Wei J, Su S, Qiu J. Novel fluorescence resonance energy transfer optical sensors for vitamin B12 detection using thermally reduced carbon dots. New J Chem. 2014:39(1):501-7.

89. Dolai KS, Jelinek R. Chemical carbon-dot-aerogel sensor for aromatic volatile organic compounds. Sens Actuators B Chem. 2017;241:607-13.

90. Zheng M, Ruan S, Liu S, Sun T, Qu D, Zhao H, Xie Z, Gao H, Jing X, Sun $Z$. Self-targeting fluorescent carbon dots for diagnosis of brain cancer cells. ACS Nano. 2015;9(11):11455-61.

91. Fong J, Chin S, Ng S. A unique "turn-on" fluorescence signaling strategy for highly specific detection of ascorbic acid using carbon dots as sensing probe. Biosens Bioelectron. 2016;85:844-52.

92. Li H, He X, Liu Y, Yu H, Kang Z, Lee S. Synthesis of fluorescent carbon nanoparticles directly from active carbon via a one-step ultrasonic treatment. Mater Res Bull. 2011;46(1):147-51.

93. Zhu S, Zhang J, Qiao C, Tang S, Li Y, Yuan W, Li B, Tian L, Liu F, Hu R, Gao $H$, Wei $H$, Zhang $H$, Sun $H$, Yang B. Strongly green-photoluminescent graphene quantum dots for bioimaging applications. Chem Commun. 2011;47(24):6858-60.

94. Qiao ZA, Wang Y, Gao Y, Li H, Dai T, Liu Y, Huo Q. Commercially activated carbon as the source for producing multicolor photoluminescent carbon dots by chemical oxidation. Chem Commun. 2010;46(46):8812-4.

95. Peng J, Gao W, Gupta BK, Liu Z, Romero-Aburto R, Ge L, Song L, Alemany LB, Zhan X, Gao G, Vithayathil SA, Kaipparettu BA, Marti AA, Hayashi T, Zhu JJ, Ajayan PM. Graphene quantum dots derived from carbon fibers. Nano Lett. 2012:12(2):844-9.

96. Zhang M, Bai L, Shang W, Xie W, Ma H, Fu Y, Fang D, Sun H, Fan L, Han M, Liu C, Yang S. Facile synthesis of water-soluble, highly fluorescent graphene quantum dots as a robust biological label for stem cells. J Mater Chem. 2012;22(15):7461-7.

97. Dong Y, Chen C, Zheng X, Gao L, Cui Z, Yang H, Guo C, Chi Y, Li CM. One-step and high yield simultaneous preparation of single- and multilayer graphene quantum dots from CX-72 carbon black. J Mater Chem. 2012;22(18):8764-6.

98. Hsu PC, Chang HT. Synthesis of high-quality carbon nanodots from hydrophilic compounds: role of functional groups. Chem Commun. 2012;48(33):3984-6

99. Song Y, Shi W, Chen W, Li X, Ma H. Fluorescent carbon nanodots conjugated with folic acid for distinguishing folate-receptor-positive cancer cells from normal cells. J Mater Chem. 2012;22(25):12568-73.

100. Lai CW, Hsiao YH, Peng YK, Chou PT. Facile synthesis of highly emissive carbon dots from pyrolysis of glycerol gram scale production of carbon dots $/ \mathrm{mSiO}_{2}$ for cell imaging and drug release. J Mater Chem. 2012;22(29):14403-9.

101. Pan D, Guo L, Zhang J, Xi C, Xue Q, Huang H, Li J, Zhang Z, Yu W, Chen Z, Li Z, Wu M. Cutting sp2 clusters in graphene sheets into colloidal graphene quantum dots with strong green fluorescence. J Mater Chem. 2013:22(8):3314-8.

102. Chen B, Li F, Li S, Weng W, Guo H, Guo T, Zhang X, Chen Y, Huang T, Hong $X$, You S, Lin Y, Zeng K, Chen S. Large scale synthesis of photoluminescent carbon nanodots and their application for bioimaging. Nanoscale. 2013;5(5):1967-71

103. Hu C, Liu Y, Yang Y, Cui J, Huang Z, Wang Y, Yang L, Wang H, Xiao Y, Rong J. One-step preparation of nitrogen-doped graphene quantum dots from oxidized debris of graphene oxide. J Mater Chem B. 2013;1(1):39-42.

104. Liu Q, Guo B, Rao Z, Zhang B, Gong JR. Strong two-photon-induced fluorescence from photostable, biocompatible nitrogen-doped graphene quantum dots for cellular and deep-tissue imaging. Nano Lett. 2013;13(6):2436-41.

105. Zhou L, Geng J, Liu B. Graphene Quantum Dots from Polycyclic Aromatic Hydrocarbon for Bioimaging and Sensing of $\mathrm{Fe}^{3+}$ and Hydrogen Peroxide. Part Part Syst Charact. 2013;30(12):1086-92.

106. Sun Y, Wang S, Li C, Luo P, Tao L, Wei Y, Shi G. Large scale preparation of graphene quantum dots from graphite with tunable fluorescence properties. Phys Chem Chem Phys. 2013;15(24):9907-13.

107. Wang L, Yin Y, Jain A, Zhou HS. Aqueous-phase synthesis of highly luminescent, nitrogen-doped carbon dots and their application as bioimaging agents. Langmuir. 2014;30(47):14270-5.

108. Ge J, Jia Q, Liu W, Guo L, Liu Q, Lan M, Zhang H, Meng X, Wang P. Redemissive carbon dots for fluorescent, photoacoustic, and thermal theranostics in living mice. Adv Mater. 2015;27(28):4169-77.

109. Krishna AS, Radhakumary C, Sreenivasan K. Detection and imaging of fatty plaques in blood vessels using functionalized carbon dots. Anal Methods. 2015;7(22):9482-8.

110. Parvin N, Mandal TK. Dually emissive P, N-co-doped carbon dots for fluorescent and photoacoustic tissue-imaging in living mice. Microchim Acta. 2017;184(4):1117-25.

111. Borse V, Thakur M, Sengupta S, Srivastava R. N-doped multifluorescent carbon dots for 'turn off-on' silver-biothiol dual sensing and mammalian cell imaging application. Sens Actuators B Chem. 2017; 248:481-92.

112. Yang W, Zhang H, Lai J, Peng X, Hu Y, Gu W, Ye L. Carbon dots with red-shifted photoluminescence by fluorine doping for optical bioimaging. Carbon. 2018:128:78-85.

113. Ghosal K, Ghosh A. Carbons dots: the next generation platform for biomedical applications. Mater Sci Eng C Mater Biol Appl. 2019;96:887-903.

114. Zhou L, Li Z, Liu Z, Ren J, Qu X. Luminescent carbon dot-gated nano vehicles for $\mathrm{pH}$-triggered intracellular controlled release and imaging. Langmuir. 2013;29(21):6396-403.

115. Yang C, Thomsen RP, Ogaki R, Kjems J, Teo BM. Ultrastable green fluorescence carbon dots with a high quantum yield for bioimaging and use as theranostic carriers. J Mater Chem B. 2015;3(22):4577-84.

116. Wang BB, Wang SJ, Wang YF, Lv Y, Wu H, Ma XJ, Tan MQ. Highly fluorescent carbon dots for visible sensing of doxorubicin release based on efficient nanosurface energy transfer. Biotechnol Lett. 2016;38(1):191-201.

117. Kong T, Hao L, Wei Y, Cai X, Zhu B. Doxorubicin conjugated carbon dots as a drug delivery system for human breast cancer therapy. Cell Prolif. 2018:51(5):12488.

118. Mewada A, Pandey S, Thakur M, Jadhav D, Sharon M. Swarming carbon dots for folic acid-mediated delivery of doxorubicin and biological imaging. J Mater Chem B. 2013;2(6):698-705

119. Li S, Amat D, Peng Z, Vanni S, Raskin S, Angulo GD, Othma AM, Graham RM, Leblanc RM. Transferrin conjugated nontoxic carbon dots for doxorubicin delivery to target pediatric brain tumor cells. Nanoscale. 2016:8(37):16662-9.

120. Gao N, Yang W, Nie H, Gong Y, Jing J, Gao L, Zhang X. Turn-on theranostic fluorescent nanoprobe by electrostatic self-assembly of carbon dots with doxorubicin for targeted cancer cell imaging, in vivo hyaluronidase analysis, and targeted drug delivery. Biosens Bioelectron. 2017;96:300-7.

121. Sun $T$, Zheng $M, X i e Z$, Jing $X$. Supramolecular hybrids of carbon dots with doxorubicin: synthesis, stability and cellular trafficking. Mater Chem Front. 2017;1(2):354-60.

122. Zheng M, Liu X, Li J, Qu D, Zhao H, Guan X, Hu X, Xie Z, Jing X, Sun Z. Integrating oxaliplatin with highly luminescent carbon dots: an unprecedented theranostic agent for personalized medicine. Adv Mater. 2014;21(26):3554-60.

123. Wu YF, Wu HC, Kuan CH, Lin CJ, Wang LW, et al. Multi-functionalized carbon dots as theranosticnanoagent for gene delivery in lung cancer therapy. Scientific Rep. 2016;6:21170. 
124. Zhang M, Zhao X, Fang Z, Niu Y, Lou J, Wu Y, Zou S, Xia S, Sun M, Du F. Fabrication of HA/PEl-functionalized carbon dots for tumor targeting, intracellular imaging and gene deliver. RSC Adv. 2017;7(6):3369-75.

125. Luo TY, He X, Zhang J, Chen P, Liu YH, Wan HJ, Yu XQ. Photoluminescent F-doped carbon dots prepared by ring-opening reaction for gene delivery and cell imaging. RSC Adv. 2018;8(11):6053-62.

126. Hana M, Zhub S, Luc S, Songa Y, Fenga T, Taoa S, Liua J, Yanga B. Recent progress on the photocatalysis of carbon dots: classification, mechanism, and applications. Nanotoday. 2018;19:201-18

127. Jiang Y, Wang Z, Dai Z. Preparation of silicon-carbon-based dots@ dopamine and its application in intracellular $\mathrm{Ag}+$ detection and cell imaging. ACS Appl Mater Interfaces. 2016;8(6):3644-50.

128. Lu W, Gong X, Yang Z, Zhang Y, Hu Q, Shuang S, Dong C, Choi MM. High quality water-soluble luminescent carbon dots for multicolor patterning, sensors, and bioimaging. RSC Adv. 2015;5(22):16972-9.

129. Chen Z, Wang J, Miao H, Wang L, Wu S, Yang X. Fluorescent carbon dots derived from lactose for assaying folic acid. Sci China Chem. 2015:59(4):487-92.

130. Lan J, Liu C, Gao M, Huang C. An efficient solid-state synthesis of fluorescent surface carboxylated carbon dots derived from C60 as a label-free probe for iron ions in living cells. Talanta. 2015;144(1):93-7.

131. Yang J, He X, Chen L, Zhang Y. The selective detection of galactosebased on boronic acid functionalized fluorescent carbon dots. Anal Methods. 2016;8(47):8345-51.

132. Bhattacharya S, Sarkar R, Chakraborty B, Porgador A, Jelinek R. Nitric oxide sensing through azo-dye formation on carbon dots. ACS Sens, 2017:2(8):1215-24.

133. Iqbal A, lqbal K, Xu L, Li B, Gong D, Liu X, Guo Y, Liu W, Qin W, Guo H. Heterogeneous synthesis of nitrogen-doped carbon dots prepared via anhydrous citric acid and melamine for selective and sensitive turn on-off-on detection of $\mathrm{Hg}(\mathrm{II})$, glutathione and its cellular imaging. Sens Actuators B Chem. 2018;255(1):1130-8.

134. Zhou L, Lin Y, Huang Z, Ren J, Qu X. Carbon nanodots as fluorescence probes for rapid, sensitive, and label-free detection of $\mathrm{Hg} 2+$ and biothiols in complex matrices. Chem Commun. 2012;48(8):1147-9.

135. Xu Q, Su R, Chen Y, Sreenivasan ST, Li N, Zheng X, Zhu J, Pan H, Li W, Xu C, Xia Z, Dai L. Metal Charge Transfer Doped Carbon Dots with Reversibly Switchable, Ultra-High Quantum Yield Photoluminscence. J Colloid Interface Sci. 2018;1(4):1886-93.

136. Pan $X$, Zhang $Y$, Sun $X$, Pan W, Wang J. A green emissive carbon-dotbased sensor with diverse responsive manners for multi-mode sensing. Analyst. 2018;143:5812-21.

137. Wang BB, Jin JC, Xu ZQ, Jiang ZW, Li X, Jiang FL, Liu Y. Single-step synthesis of highly photoluminescent carbon dots for rapid detection of Hg2 + with excellent sensitivity. J Colloid Interface Sci. 2019;551:101-10.

138. Li B, Ma H, Zhang B, Qian J, Cao T, Feng H, Li W, Dong Y, Qin W. Dually emitting carbon dots as fluorescent probes for ratiometric fluorescent sensing of $\mathrm{pH}$ values, mercury(II), chloride and $\mathrm{Cr}(\mathrm{VI})$ via different mechanisms. Mikrochim Acta. 2019;186(6):341.

139. Zhang YL, Wang L, Zhang HC, Liu Y, Wang HY, Kang ZH, Lee ST. Graphitic carbon quantum dots as a fluorescent sensing platform for highly efficient detection of Fe3p ions. RSC Adv. 2013;3(11):3733-8.

140. Kaur N, Mehta A, Mishra A, Chaudhary S, Rawat M, Basu S. Amphiphilic carbon dots derived by cationic surfactant for selective and sensitive detection of metal ions. Mater Sci Eng C Mater Biol Appl. 2018;95(1):72-7.

141. Wu J, Feng Y, Shao Y, Sun Y. High quality nitrogen and silicon co-doped carbon dots (N/Si-CDs) for Fe3+ sensing. J Nanosci Nanotechnol. 2018;18(6):4196-203.

142. Sun $Y$, Wang $X$, Wang $C$, Tong $D$, Wu $Q$, Jiang $K$, Jiang $Y$, Wang $C$, Yang $M$. Red emitting and highly stable carbon dots with dual response to $\mathrm{pH}$ values and ferric ions. Microchim Acta. 2018:185:83.

143. Hu S, Zhao Q, Chang Q, Yang J, Liu J. Enhanced performance of Fe3p detection via fluorescence resonance energy transfer between carbon quantum dots and Rhodamine B. RSC Adv. 2014;4(77):41069-75.

144. Zhou M, Zhou Z, Gong A, Zhang Y, Li Q. Synthesis of highly photoluminescent carbon dots via citric acid and Tris for iron(III) ions sensors and bioimaging. Talanta. 2015;143:107-13.

145. Miao X, Yan X, Qu D, Li D, Tao F, Sun Z. Red emissive sulfur, nitrogen codoped carbon dots and their application in ion detection and theranostics. ACS Appl Mater Interfaces. 2017;9(22):18549-56.
146. Qian Z, Ma J, Shan X, Feng H, Shao L, Chen J. Highly luminescent $\mathrm{N}$-doped carbon quantum dots as an effective multifunctional fluorescence sensing platform. Chemistry. 2014;20(8):2254-63.

147. Ren G, Zhang Q, Li S, Fu S, Chai F, Wang C, Qu F. One pot synthesis of highly fluorescent $\mathrm{N}$ doped $\mathrm{C}$-dots and used as fluorescent probe detection for $\mathrm{Hg}^{2+}$ and $\mathrm{Ag}^{+}$in aqueous solution. Sens Actuators B Chem. 2017;243:244-53.

148. Li J, Zuo G, Pan X, Wei W, Qi X, Su T, Dong W. Nitrogen-doped carbon dots as a fluorescent probe for the highly sensitive detection of $\mathrm{Ag}+$ and cell imaging. Luminescence. 2018;33(1):243-8.

149. Wang F, Lu Y, Chen Y, Sun J, Liu Y. Novel colorimetric nanosensor based on the aggregation of AuNP triggered by carbon quantum dots for detection of Ag+ ions. ACS Sustain Chem Eng. 2018;6(3):3706-13.

150. Qin J, Zhang LM, Yang R. Powder carbonization to synthesize novel carbon dots derived from uric acid for the detection of $\mathrm{Ag}(\mathrm{I})$ and glutathione. Spectrochim Acta Part A Mol Biomol Spectrosc. 2019;207:54-60

151. Qin Z, Wang W, Zhan X, Du X, Zhang Q, Zhang R, Li K, Li J, Xu W. Onepot synthesis of dual carbon dots using only an $N$ and $S$ coexisted dopant for fluorescence detection of $\mathrm{Ag}+$. Spectrochim Acta A Mol Biomol Spectrosc. 2019;5(208):162-71.

152. Sun X, Wu L, Shen J, Gao X, Wen C, Liu B, Wang H. Highly selective and sensitive sensing for $\mathrm{Al} 3+$ and $\mathrm{F}$ - based on green photoluminescent carbon dots. RSC Adv. 2016;6(99):97346-51.

153. Devi P, Thakur A, Chopra S, Kaur N, Kumar P, Singh N, Kumar M, Math SP, Nayak MK. Ultrasensitive and selective sensing of selenium using nitrogen-rich ligand interfaced carbon quantum dots. ACS Appl Mater Interfaces. 2017;9(15):13448-56.

154. Chen J, Liu J, Li J, Xu L, Qiao Y. One-pot synthesis of nitrogen and sulfur co-doped carbon dots and its application for sensor and multicolor cellular imaging. J Colloid Interface Sci. 2017:485:167-74.

155. Chandra S, Chowdhuri AR, Laha D, Sahu SK. Fabrication of nitrogen- and phosphorous-doped carbon dots by the pyrolysis method for iodide and iron(III) sensing. Luminescence. 2018;33(2):336-44.

156. Zhang J, Yan J, Wang Y, Zhang Y. One-step hydrothermal approach to synthesis carbon dots from $\mathrm{D}$-sorbitol for detection of iron(III) and cell imaging. J Nanosci Nanotechnol. 2018;18(7):4457-63.

157. Qu D, Zheng M, Du P, Zhou Y, Zhang L, Li D, Tan H, Zhao Z, Xie Z, Sun Z Highly luminescent S, N co-doped graphene quantum dots with broad visible absorption bands for visible light photocatalysts. Nanoscale. 2013:5:12272-7.

158. Yu H, Zhao Y, Zhou C, Shang L, Peng Y, Cao Y, Wu LZ, Tung CH, Zhang T. Carbon quantum dots/TiO2 composites for efficient photocatalytic hydrogen evolution. J Mater Chem A. 2014;10(2):3344-51.

159. Wang J, Gao M, Ho GW. Bidentate-complexes-derived TiO2/carbon dots photocatalysts: in situ synthesis, versatile heterostructures, and enhanced H2 evolution. J Mater Chem. 2014;2(16):5703-9.

160. Martins NCT, Angelo J, Girao AV, Trindade T, Andrade L. N-doped carbon quantum dots/TiO2 composite with improved photocatalytic activity. Appl Catal B. 2016;193:67-74.

161. Cai A, Wang Q, Chang Y, Wang X. Graphitic carbon nitride decorated with S, N co-doped graphene quantum dots for enhanced visible-lightdriven photocatalysis. J Alloys Compd. 2017:692:183-9.

162. Zhang Z, Wu L, Wang P, Zhang Y, Wan S, Guo X, Jin W, Zhang J. Carbon quantum dots modified La2Ti2O7 nanosheets for visible light photocatalysis. Mater Lett. 2018;230(1):72-5.

163. Chen J, Che H, Huang K, Liu C, Shi W. Fabrication of a ternary plasmonic photocatalyst CQDs/Ag/Ag2O to harness charge flow for photocataIytic elimination of pollutants. Appl Catal B. 2016;192(5):134-44.

164. Hong Y, Meng Y, Zhang G, Yin B, Zhao Y. Facile fabrication of stable metal-free CQDs/g-C3N4 heterojunctions with efficiently enhanced visible-light photocatalytic activity. Sep Purif Technol. 2016;171:229-37.

165. Que $\mathrm{Q}$, Xing $\mathrm{Y}, \mathrm{He} Z$, Yang Y, Yin X. Bi2O3/Carbon quantum dots hetero structured photocatalysts with enhanced photocatalytic activity. Mater Lett. 2017;209:220-3.

166. Yang H, Zhang S, Cao R, Deng X, Li Z, Xu X. Constructing the novel ultrafine amorphous iron oxyhydroxide/g-C3N4 nanosheets heterojunctions for highly improved photocatalytic performance. Sci Rep. 2017;7(1):8686 
167. Li X, Wang Q, Zhao Y, Wu W, Chen J, Meng H. Green synthesis and photo-catalytic performances for $\mathrm{ZnO}$-reduced graphene oxide nanocomposites. J Colloid Interface Sci. 2013;411:69-75.

168. Mao J, Peng T, Zhang X, Li K, Ye L, Zan L. Effect of graphitic carbon nitride microstructures on the activity and selectivity of photocatalytic CO2 reduction under visible light. Catal Sci Technol. 2013;3(5):1253-60.

169. Sahu S. development and evaluation of carbon-based quantum dots for carbon dioxide photoconversion. Ph.D. Thesis, Clemson University, December 2014.

170. Cao L, Sahu S, Anilkumar P, Bunker CE, Xu J, Fernando KAS, Wang P, Guliants EA, Tackett KN, Sun YP. Carbon nanoparticles as visible-light photocatalysts for efficient CO2 conversion and beyond. J Am Chem Soc. 2011;133(13):4754-7.

171. Yan M, Hua Y, Zhu F, Sun L, Gu W, Shi W. Constructing nitrogen-doped graphene quantum dots-ZnNb2O6/g-C3N4 catalysts for hydrogen production under visible light. Appl Catal B Environ. 2017;206:531-7.

172. Muthulingam $S$, Lee $\mathbb{H}$, Uthirakumar P. Highly efficient degradation of dyes by carbon quantum dots/N-doped zinc oxide (CQD/N-ZnO) photocatalyst and its compatibility on three different commercial dyes under daylight. J Colloid Interface Sci. 2015:455:101-9.

173. Bourlinos AB, Rathi AK, Gawande MB, Hola K, Goswami A. Fe(III)functionalized carbon dots-highly efficient photoluminescence redox catalyst for hydrogenations of olefins and decomposition of hydrogen peroxide. Appl Mater Today. 2017;7:179-84

174. Sharma G, Bhogal S, Naushad M, Inamuddin I, Kumar A. Microwaveassisted fabrication of $\mathrm{La} / \mathrm{Cu} / \mathrm{Zr} /$ carbon dots trimetallic nanocomposites with their adsorption vs photocatalytic efficiency for remediation of persistent organic pollutants. J Photochem Photobiol A Chem. 2017;347:235-43.

175. Ma Z, Ming H, Huang H, Liu Y, Kang Z. One-step ultrasonic synthesis of fluorescent $\mathrm{N}$-doped carbon dots from glucose and their visible-light sensitive photocatalytic ability. New J Chem. 2012;36(4):861-4.

176. Wang J, Tang L, Zeng G, Deng Y, Dong H. OD/2D interface engineering of carbon quantum dots modified Bi2WO6 ultrathin nanosheets with enhanced photo activity for full spectrum light utilization and mechanism insight. Appl Catal B. 2018;222:115-23.

177. Mehta A, Mishra A, Kainth S, Basu S. Carbon quantum dots/TiO2 nanocomposite for sensing of toxic metals and photodetoxification of dyes with kill waste by waste concept. Mater Des. 2018;155:485-93.

178. Huang Y, Liang Y, Rao Y, Zhu D, Cao JJ. Environmental friendly carbon quantum dots/ZnFe2O4 photocatalysts: characterization, biocompatibility, and mechanisms for $\mathrm{NO}$ removal. Environ Sci Technol. 2017;51(5):2924-33.

179. Wang F, Wang Y, Feng Y, Zeng Y, Xie Z. Novel ternary photocatalyst of single atom-dispersed silver and carbon quantum dots co-loaded with ultrathin g-C3N4 for broad-spectrum photocatalytic degradation of naproxen. Appl Catal B. 2018;221:510-20.

180. Xie Z, Feng Y, Wang F, Chen D, Zhang Q, Zeng Y, Lv W, Liu G. Construction of carbon dots modified MoO3/g-C3N4 Z-scheme photocatalyst with enhanced visible-light photocatalytic activity for the degradation of tetracycline. Appl Catal B. 2018;229:96-104.

181. Hassan M, Gomes VG, Dehghani A, Ardekani SM. Engineering carbon quantum dots for photomediated theranostics. Nano Res. 2018:1(11):1-41.

182. Ge J, Jia Q, Liu W, Guo L, Liu Q, Lan M, Zhang H, Meng X, Wang P. Red-emissive carbon dots for fluorescent, photoacoustic, and thermal theranostics in living mice. Adv Mater. 2015;28(27):4169-77.

183. Zheng M, Li Y, Liu S, Wang W, Xie Z, Jing X. One-pot to synthesize multifunctional carbon dots for near-infrared fluorescence imaging and photothermal cancer therapy. ACS Appl Mater Interfaces. 2016:8(36):23533-41.

184. Li D, Han D, Qu SN, Liu L, Jing PT, Zhou D, Ji WY, Wang XY, Zhang TF, Shen DZ. Supra-(carbon nanodots) with a strong visible to near-infrared absorption band and efficient photothermal conversion. Light Sci Appl. 2016:5:e16120.

185. Beack S, Kong WH, Jung HS, Do IH, Han S, Kim H, Kim KS, Yun SH, Hahn SK. Photodynamic therapy of melanoma skin cancer using carbon dot-chlorin e6-hyaluronateconjugate. Acta Biomater. 2015:26:295-305.

186. Zheng DW, Li B, Li CX, Fan JX, Lei Q, Li C, Xu Z, Zhang XZ. Carbondot-decorated carbon nitride nanoparticles for enhanced photodynamic therapy against hypoxic tumor via water splitting. ACS Nano. 2016;10(9):8715-22.

187. Wu F, Su H, Cai Y, Wong WK, Jiang W, Zhu X. Porphyrin-implanted carbon nanodots for photoacoustic imaging and in vivo breast cancer ablation. ACS Appl Biol Mater. 2018;1(1):110-7.

188. Hua XW, Bao YW, Wu FG. Fluorescent carbon quantum dots with intrinsic nucleolus-targeting capability for nucleolus imaging and enhanced cytosolic and nuclear drug delivery. ACS Appl Mater Interfaces. 2018;10(13):10664-77.

189. Guo XL, Ding ZY, Deng SM, Shen XC, Jiang BP, Liang H. A novel strategy of transition-metal doping to engineer absorption of carbon dots for near-infrared photothermal/photodynamic therapies. Carbon. 2019;19(134):519-30.

\section{Publisher's Note}

Springer Nature remains neutral with regard to jurisdictional claims in published maps and institutional affiliations.
Ready to submit your research? Choose BMC and benefit from:

- fast, convenient online submission

- thorough peer review by experienced researchers in your field

- rapid publication on acceptance

- support for research data, including large and complex data types

- gold Open Access which fosters wider collaboration and increased citations

- maximum visibility for your research: over $100 \mathrm{M}$ website views per year

At BMC, research is always in progress.

Learn more biomedcentral.com/submissions 